Army-Baylor University Graduate Program in Health Care Administration Graduate Management Project

\title{
A Cultural Assessment of Tripler Regional Medical Center
}

\author{
Presented To \\ LTC Timothy McCarthy, MS \\ In Partial Fulfillment of the Degree of \\ Master in Health Administration
}

\author{
By \\ Major John R. Lee, Medical Service, MS, CHE \\ Tripler Regional Medical Center \\ 15 May 1997
}




\section{REPORT DOCUMENTATION PAGE}

Public reporting burden for this collection of information is estimated to aversge 1 hour per response, including the time for raviewing instructions, searching axisting data sourcess, gathering and maint aining the dato needed, and completing and reviewing the collaction of information. Send comments regarding this burden estimate or any other aspect of this

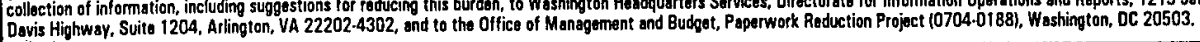

\begin{tabular}{|l|l|l|}
\hline 1. AGENCY USE ONLY (Leave blank) & $\begin{array}{r}\text { 2. REPORT DATE } \\
\text { MAY 1997 }\end{array}$ & $\begin{array}{l}\text { 3. REPORT TYPE AND DATES COVERED } \\
\text { FINAL REPORT (7-96 TO 7-97) }\end{array}$ \\
\hline
\end{tabular}

4. TITLE AND SUBTITLE

5. FUNDING NUMBERS

A CULTURAL ASSESSMENT OF TRIPLER REGIONAL MEDICAL CENTER

6. AUTHOR(S)

MAJ JOHN R. LEE, MS

7. PERFORMING ORGANIZATION NAME(S) AND ADDRESS(ES)

TRIPLER REGIONAL MEDICAL CENTER

HONOLULU, HI

8. PERFORMING ORGANIZATION REPORT NUMBER

9. SPONSORING / MONITORING AGENCY NAME(S) AND ADDRESS(ES)

10. SPONSORING / MONITORING

US ARMY MEDICAL DEPARTMENT CENTER AND SCHOOL AGENCY REPORT NUMBER

BLDG 2841 MCCS-HRA (US ARMY-BAYLOR PROGRAM IN HCA)

3151 SCOTT RD SUITE 1411

FORT SAM HOUSTON TEXAS 78234-6135

11. SUPPLEMENTARY NOTES

12a. DISTRIBUTION / AVAILABILITY STATEMENT

12b. DISTRIBUTION CODE

APPROVED FOR PUBLIC RELEASE; DISTRIBUTION IS UNLIMITED

13. ABSTRACT (Maximum 200 words)

Can satisfaction of an organization be improved by using Total Quality Management methods? Can the changes in satisfaction be measured and quantified using a survey instrument? These were just a few of the questions facing the leadership at Tripler Regional Medical Center. Tripler Regional Medical Center, like all other military hospitals, is at a crossroad. The beneficiaries of military medicine are now being offered choices in whether or not to seek care in military facilities. The revenues for Tripler are being based primarily on the number of beneficiaries who choose to seek care at this hospital. Whether or not Tripler is able to retain its position as the facility of choice for its target population will be based on the ability to add value to the beneficiaries. The path Tripler Regional Medical Center has chosen to achieve the level of service quality required to sustain or grow its customer base is through embracing Total Quality Management (TQM). Over the past two years, Tripler has invested heavily in TQM training and in employing TQM management methods. The goals of this training include improvement in management, service quality, and in employee satisfaction, among other goals. A central part of a quality program is the systematic use of measures to assess critical aspects of system performance. This study will attempt to quantify whether the Tripler quality effort has resulted in quantifiable improvements in staff satisfaction. The study will use a modified Litwin-Stringer Organization Climate Questionnaire for data collection. Both descriptive and inferential statistics methods will be used in analysis of the data. Results of this study will be compared to findings of a similar study done two years previous. The methods conducted in this study will replicate the methods used in the earlier study in order to better enable effective analysis.

\begin{tabular}{l}
\hline 14. SUBJECT TERMS \\
TOTAL QUALITY MANAGEMENT (TQM) \\
\hline $\begin{array}{l}\text { 17. SECURITY CLASSIFICATION } \\
\text { OF REPORT } \\
\text { UNCLASSIFIED }\end{array}$ \\
\hline
\end{tabular}

NSN 7540.01-280-5500

\begin{tabular}{|c|c|}
\hline \multirow{2}{*}{} & $\begin{array}{c}\text { 15. NUMBER OF PAGES } \\
77\end{array}$ \\
\cline { 2 - 3 } & 16. PRICE CODE \\
19. SECURITY CLASSIFICATION \\
$\begin{array}{c}\text { OF ABSTRACT } \\
\text { UNCLASSIFIED }\end{array}$ & 20. LIMITATION OF ABSTRACT \\
UNLIMITED
\end{tabular}




\begin{abstract}
Can satisfaction of an organization be improved by using Total Quality Management methods? Can the changes in satisfaction be measured and quantified using a survey instrument? These were just a few of the questions facing the leadership at Tripler Regional Medical Center.

Tripler Regional Medical Center, like all other military hospitals, is at a crossroad. The beneficiaries of military medicine are now being offered choices in whether or not to seek care in military facilities. The revenues for Tripler are being based primarily on the number of beneficiaries who choose to seek care at this hospital. Whether or not Tripler is able to retain its position as the facility of choice for its target population will be based our ability to add value to our beneficiaries. The path Tripler Regional Medical Center has chosen to achieve the level of service quality required to sustain or grow our customer base is through embracing Total Quality Management (TQM).

Over the past two years, Tripler has invested heavily in TQM training and in employing TQM management methods. The goals of this training include improvement in management, service quality, and in employee satisfaction, among other goals. A central part of a quality program is the systematic use of measures to assess critical aspects of system performance.

This study will attempt to quantify whether the Tripler quality effort has resulted in quantifiable improvements in staff satisfaction. The study will use a modified LitwinStringer Organizational Climate Questionnaire for data collection. Both descriptive and inferential statistics methods will be used in analysis of the data.

Results of this study will be compared to the findings of a similar study done two years previous. The methods conducted in this study will replicate the methods used in the earlier study in order to better enable effective analysis.
\end{abstract}




\section{TABLE OF CONTENTS}

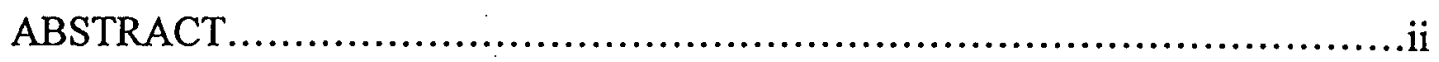

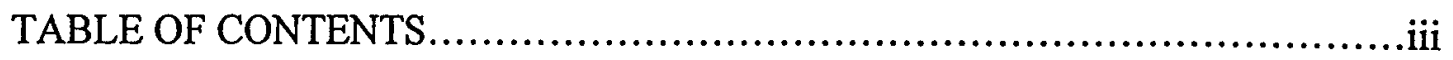

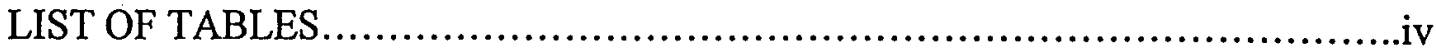

Chapter

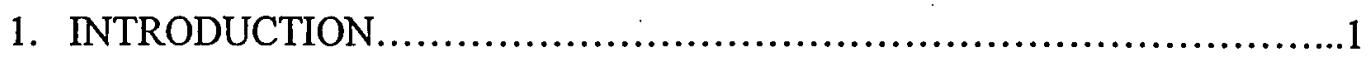

Conditions which Prompted this Study ....................................

Statement of the Management Question ...................................

Literature Review...........................................................

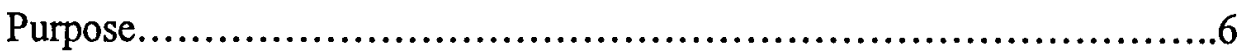

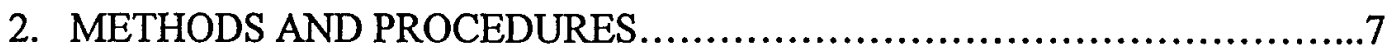

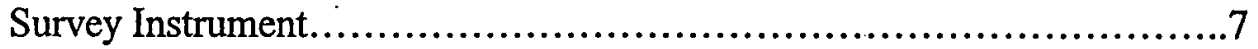

Survey Reliability ....................................................

Target Population...................................................... 10

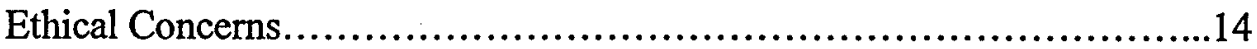

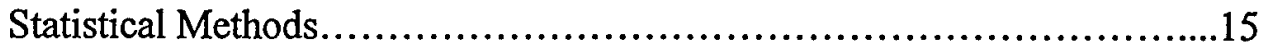

3. EXPECTED FINDINGS AND UTILITY OF RESULTS......................17

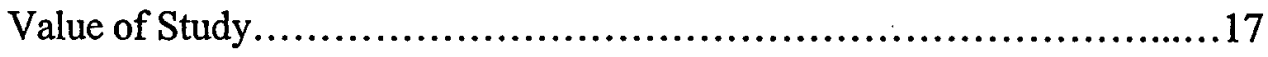

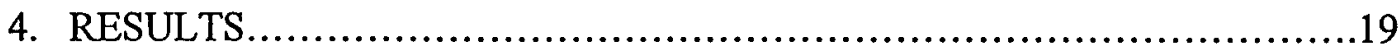

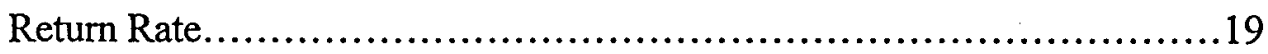

Demographic Characteristics.............................................20

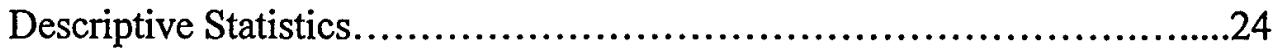

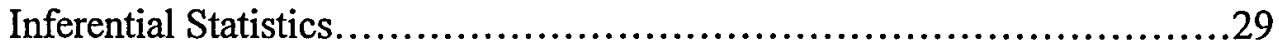

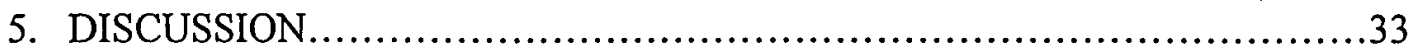

Occupational Status and Satisfaction.....................................34

Service Status and Satisfaction..............................................34

An Analysis of Associated Causes in Difference in the Population............35

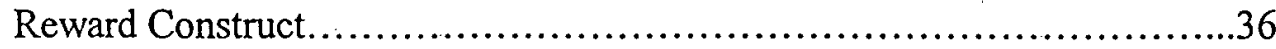

6. RECOMMENDATIONS AND CONCLUSIONS............................37 


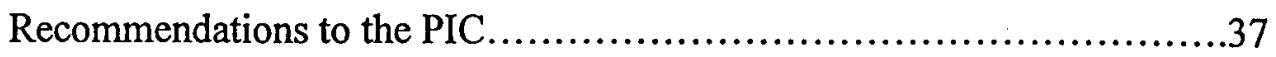

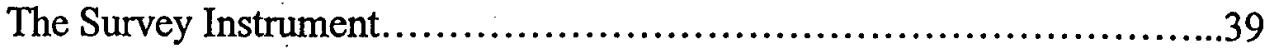

Conclusions.....................................................40

Appendix

1. Tripler Regional Medical Center Staff Cultural Assessment Survey.............41

2. One-way ANOVA Results for Occupation................................52

3. One-way ANOVA results for Service Status...............................63

4. Mean Construct and Select Question Comparison...........................69

TABLE OF CONTENTS ........................................................... 


\section{LIST OF TABLES}

Table

1. Sample Demographic and Return Rates...................................19

2. Demographic Characteristics of Survey Respondents.......................21

3. Mean and Standard Deviation for 1996 and 1994 Survey....................25

4. Construct Variable Means Comparison..................................27

5. Alpha Coefficient..................................................28

6. Differences Among Occupational Categories.............................30

7. Differences Among Service Status........................................31 


\section{CHAPTER 1}

\section{INTRODUCTION}

An organization's most important asset is its employees. The ability to unleash the "human factor" is often what distinguishes the superior organization from the average. Tripler Regional Medical Center (TAMC) adopted Total Quality Management (TQM) as its management philosophy in 1994. Batalden suggests that "employee mindedness" is an essential principle in the success of implementing TQM in health care organizations (Gustafson and Hundt 1995). In truly expressing employee mindedness, organizations can remove the organizational barriers that hinder peak performance of the human factor (Ibid.). Adams suggests that organizations can obtain corporate peak performance only if employees perform at peak levels (Lickman et al. 1993). The principle goal of managing organizational culture is to enhance individual and corporate performance (Fottler et al. 1994). Research shows a significant correlation between senior leaders understanding of organizational culture and success in shaping and sustaining TQM in organizations (Rakich, Longest and Darr 1992).

\section{Conditions which Prompted this Study}

Organizational culture has been called a "pivotal factor" in successful TQM implementation (Carmen et al. 1996). Organizational culture can be a difficult factor for a health care executive to quantify. Philip Crosby calls culture "the predictable behavior in a group or an organization" that result from what employees have been led to believe works and by examples set by leaders (Crosby 1987). Terrence Deal suggests that 
organizational culture is the "unconscious, taken-for-granted, elusive, shared pattern of values that powerfully shapes" meaning and behavior within the organization (Solbach et al. 1990). Martin Maehr describes organizational culture as the collective goals and meaning shared by the employees of an organization (Ibid.). These collective goals and meanings, according to Maehr, shape the employee's level of satisfaction and influence their commitment to the organization.

Any attempt to successfully change an organization requires continuous assessment of organizational culture (Fottler 1994). The debate over how to assess organizational culture focuses on the pros and cons of qualitative or quantitative methods. Most researchers agree that quantitative methods are best suited for assessing organizational values, norms or beliefs (lbid.).

Tripler conducted a baseline cultural assessment study in 1994 to gain an understanding of the attitudes and perceptions of the hospital staff prior to implementing TQM (Floro 1994). This study helped to establish quantitative measures of the organizational climate with the intent of using this baseline in subsequent studies after implementing TQM (Ibid.). The Process Improvement Committee (PIC) chaired by the CEO of Tripler, directed that a follow-on study be conducted to determine if employee attitudes and perceptions had changed since the shift to the TQM philosophy.

\section{Statement of the Management Question}

Tripler has pursued the TQM management philosophy for more than 2 years. This pursuit has included the expenditure of considerable financial resources and employee training time. The senior leaders desired feedback on the return of the TQM investment. The baseline survey conducted in 1994 provided the leadership at Tripler 
with an understanding of the attitudes and perceptions of the staff prior to TQM implementation. The PIC directed the cultural assessment survey be repeated in order for the leadership at Tripler to ascertain whether there has been an improvement in these attitudes and perceptions. Specifically the management questions to be addressed by the repeated survey are to:

1) measure current attitudes of the staff at Tripler,

2) measure the change in attitudes since 1994 ,

3) identify problem areas,

4) develop recommendations for improvement.

\section{Literature Review}

The health care industry has been under considerable pressure to improve the quality, reduce the cost, and improve access to health care services (Motwani et al. 1996). Some writers suggest "the health care industry (in the U.S.) is in crisis" (Ernst 1994). In 1994 , National health expenditures reached $\$ 949.4$ billion, or $\$ 3,510$ per person in the United States (HCFA, 1996). That same year, the national expenditures for hospital care had grown to $\$ 338.5$ billion (www.hcfa.gov/stats/tab2kdf.txt). Given these costs, hospitals have become the prime targets of customer groups such as patients, employers, third party payers, and politicians (Ernst 1994). These groups have become increasingly dissatisfied with the outcomes of services provided by hospitals (Ibid.). This has forced hospitals to reevaluate their mode of operation and to make changes (Ibid.). Hospitals have increasingly embraced TQM and continuous quality improvement with a belief that these management philosophies will improve the quality and efficiency of health services (Carmen et al. 1996). 
Several additional forces have helped push hospitals to adopt TQM. By 1994, most hospital managers viewed the move towards TQM as inevitable, most noticeably due to the Joint Commission's requirement for this philosophy (Ernst, 1994). In 1996 the Baldrige Award, a prestigious national award based on TQM, expanded to include an assessment specifically for health care organizations (Jennings and Wesfall, 1994).

Griffith et al. (1995) proclaimed that health care in the United States is in a state of "revolution" that is creating radical and permanent changes in the system. Griffith further suggests that all institutions will be forced to adapt to these changes quickly if they wish to survive. Griffith offers TQM as a means to enable health care organization to survive these changes through dramatic improvements in quality and efficiency. With these pressures for change, the reader can understand the lure of TQM's "promise of increased effectiveness coupled with greater efficiency" and "the opportunity to achieve better outcome with fewer resources" (Counte et al. 1995).

TQM is quickly becoming widely accepted and practiced in the health care setting. This was not the case just a few years ago. As recently as 1994, one author stated that "TQM, though not a new concept, is new to the hospital industry" (emphasis added) (Ernst 1994). The fact is; however, by 1992 over 58.5 percent of hospitals practiced TQM and 35.1 percent were planning to implement TQM (Robinson 1995). Conventional wisdom states that the transition to TQM requires years to fully measure the effects of change (Boerstler 1996). The debate over the actual length of time required to measure the change brought about by TQM is hotly debated. Recent research is now indicating that less time is required to show the effects of TQM in measurable ways (Ibid.). Irrespective of recent findings, with four to six years of experience with TQM in 
health care settings, meaningful measures on the effectiveness of TQM should be available. This is in fact, now becoming true. A 1996 journal article reported on the findings of 41 recently published works concerning TQM in health care organizations (Motwani 1996). More empirical research is being published every month in leading health care journals.

Recent research found that hospitals seeking organization-wide change (TQM) must first focus on implementing cultural change (Boerstler 1996). This research found that without a clear cultural change, the impact of TQM is limited (Ibid.). Boerstler also found a clear link between a "flexible organizational culture" and successful implementation of TQM (Ibid.).

Current literature suggests a strong link between organizational culture and customer satisfaction (Carmen et al. 1996). Research shows that process improvement and improvements in employee's perceptions of empowerment produce improved customer satisfaction and improved efficiency (Ibid.). Other authors report that in select organizations devoted fully to the TQM philosophy, cost is increasing less rapidly, they have higher patient satisfaction and have higher physician ranking of quality compared to non-TQM practicing hospitals (Griffith et al. 1995).

Other research shows managers have taken for granted that TQM will benefit areas such as customer satisfaction, profitability, productivity, quality, and employee satisfaction (Bigelow and Arndt 1995). With the expectation that TQM will lead to greater quality comes the potential that process improvements may be contributed to TQM when other factors may have played a more significant role. Hawthorne showed that simply having the workforce believe that the process is being reviewed can result in 
significant improvements in productivity. Although recent empirical evidence is now beginning to link TQM with measurable improvements, more research is clearly needed.

\section{Purpose}

The purpose of this study is to determine the organizational attitudes and perceptions after 2 years of TQM implementation effort. This study will establish the current attitudes of the staff and determine if differences exist between employee categories at Tripler. The study will determine if the attitudes and perceptions of the staff at Tripler have changed since 1994. 


\section{CHAPTER 2}

\section{METHODS AND PROCEDURES}

The research method for this study is quantitative. Data will be collected for this study using a modified Litwin and Stringer Organizational Climate Questionnaire (Muchinsky 1976). A sample survey is provided as Appendix 1. Analysis of the data will be made using the computerized statistical application SPSS version 7.0 for Windows 95 . Statistical assistance will be provided by researchers in the Clinical Investigation Division and Nursing Research, Tripler Regional Medical Center.

\section{$\underline{\text { Survey Instrument }}$}

Litwin and Stringer designed the survey instrument used for this study. The original survey was developed in 1968 and contained 50 four-point Likert scaled questions (Floro 1994). The survey was designed to elicit responses from employees as to their agreement with statements about various facets of their organization (Litwin and Stringer 1968). The survey consisted of nine scales described below. The Litwin and Stringer survey given to Tripler in 1994 was modified from the original design. Floro added a tenth scale and modified the Likert scale to a five-point scale (Floro 1994).

The 1994 and the1996 survey consists of ten constructs (also called scales), with each construct composed of between 4-8 questions. The ten constructs are:

1. Structure (8 questions): The perceptions of the level of bureaucracy within the organizational structure; the feeling about the amount of rules and red tape that constrain employees and workgroups. 
2. Responsibility ( 7 questions): The feeling of being empowered to do ones job verses feeling supervisors double-check your work and decisions.

3. Reward (6 questions): The perceptions of an atmosphere that rewards individuals for a job done well; the degree that positive reinforcements are practiced as a management style verses punishment; the perception of fairness in the promotion and pay policies.

4. Risk ( 5 questions): The amount of risk and challenge from the organization and job; the level of emphasis placed on risk taking verses playing it safe.

5. Warmth (5 questions): The perception of an atmosphere of goodwill in the workgroup; the prevalence of open and friendly informal social groups.

6. Support (5 questions): The perceived amount of helpfulness of managers and coworkers; the degree of emphasis on mutual support from management and subordinates.

7. Standards (6 questions): The degree of importance placed on goals and performance standards; the emphasis of doing the right things well; the value of personnel and group goals.

8. Conflict (4 questions): The openness of managers and coworkers to different ideas and opinions; the degree to which problems are openly dealt with verses ignoring or smoothing them over.

9. Identity (4 questions): Sense of membership to the organization; feeling as a valuable member of the team; the importance the organization places on this individuality. 
10. TQM (7 questions): The perceptions of the amount of commitment from top management towards TQM; the degree of importance the employee places on TQM; the amount of knowledge by employees of TQM principles.

\section{Survey Reliability}

The literature indicates a consistent level of reliability for the proposed survey instrument (Litwin and Stringer 1968; Muchinsky 1976; Counte et al. 1992; and Floro 1994). A common test to measure survey reliability is the Cronbach's alpha, which measures the stability or internal consistency of the instrument (Cronbach 1951). A high correlation indicates high test reliability while low correlation indicates low test reliability (Spatz 1992). Reliability is critical in social science measurements. Reliability allows the researcher to assess the degree of certainty that the test results are not subject to chance variation (Ibid.). A low degree of reliability results in uncertainty that the researchers' findings from the sample mirror the actual qualities of the population (Ibid.).

Floro used randomized block ANOVAs to ascertain the Cronbach's alpha for the ten scales of the instrument (Floro 1994). Floro reported six of the ten scales as having exceptionally high reliability (above .70), two showed good reliability (above .50) and two indicated questionable reliability (Floro 1994). The two constructs with questionable reliability were conflict at .19 and responsibility at .36 (Floro 1994). The level of the coefficient required to label a social science test highly reliable is debatable. Floro and Daniel (1978) both cite an alpha above .70 as highly reliable while Spatz suggests .80 or higher. In view of the disagreement over the appropriate alpha coefficient one must achieve, this test has shown to consistently achieve high levels of reliability. 


\section{Target Population}

Tripler Regional Medical Center current workforce is about 2677 employees. Of this workforce, about 52 percent are military. The educational levels, skills, involvement in management, and responsibilities vary greatly depending on the position the employee holds. In reaching an understanding about the perceptions of the workforce, it would be useful to enable the researcher to categorize the workforce into logical workgroups in order to make meaningful comparisons. By categorizing the workforce into groupings such as physicians, nurses, and clerical staff, one could make comparisons to determine if a significant difference exists between these groups. The statistical term for breaking populations into logical groupings for the purpose of discovering patterns is known as stratification (Plesk 1994).

In order to make comparisons with the 1994 survey conducted by Floro, the proposed survey would replicate the groupings Floro devised. Floro divided the workforce into two major groupings, military and civilian (Floro 1994). Each of these groupings was further separated into seven sub-groupings; physicians, nurses, allied health professionals, technical, office and clerical support, service workers, and other. In order to aid the survey participant to correctly categorize their correct grouping, Floro included on the survey the following definitions, which will also appear on the 1996 survey:

1. Physicians: Staff and house staff (interns, residents, and fellows).

2. Registered Nurses: Clinical specialists, nurse practitioners and nurse educators. 
3. Allied Health Professionals: Medical technologists, pharmacists, dietitians, physical and occupational therapists, social workers, psychologists, dentists, veterinarians, speech pathologists, and optometrist.

4. Medical Technicians: LPNs, medical specialists, nursing assistants, radiology technicians, pharmacy technicians, PT/OT assistants, EEG/EKG technicians, respiratory/pulmonary technicians, OR technicians, and phlebotomists.

5. Office/Clerical Support: Medical records technicians, secretaries, receptionists, transcriptionists, admitting clerks, personnel and legal specialist, finance and accounting specialists, computer operators, and communications specialist.

6. Service: Food service workers, environmental service workers, supply/warehouse personnel, security officers, and craftsmen.

7. Others: Administrators, chaplains, attorneys, and engineers.

Sampling allows one to make conclusions about the target population through the collection of information from only a select portion of the population (Cooper and Emory 1995). A precondition to valid statistical inference is the random selection of the sampled population from the targeted population (Brown and Beck 1994). The aim of sampling is to allow the researcher to make statements about the global population based on the sample data (Brown and Beck 1994). The main advantage of sampling over measuring the entire population is economy (Juran 1980).

There is a difference between the two discussed populations, the sampled population and the targeted population. The sampled population is the population from which the researcher draws the sample (Daniel 1978). The target population is that which 
the researcher makes the inference (Ibid.). These two populations may not be the same. It is through the application of appropriate sampling techniques that allow the researcher to be reasonably assured that the populations are representative (Ibid.). Only then can the researcher make use of statistical inference procedures to reach conclusions about the target population (Ibid.).

Simple random sampling allows the researcher to produce a sample most likely to be representative of the population (Spatz 1993). Random sampling is also known as probability sampling, which is based on "a controlled procedure that assures that each population element is given a known nonzero chance of selection" (Cooper and Emory 1995). Random sampling can be further refined by stratification. As discussed earlier, stratification is a statistical term that refers to the separation of data into various groups for the purpose of discovering patterns and achieving greater understanding (Plsek 1994). By employing stratification the researcher can look for differences between employee groups, patient acuity, educational background, or any other area the researcher wishes to stratify.

The central limit theorem says that as the sample size gets larger, the sampling distribution of the mean will approach a normal distribution (Spatz 1993). This theory leads naturally to the question "what sample size is large enough"? As a general rule, statisticians have found that for most population distributions, once the sample size is at least 30 , the sampling distribution of the mean will be approximately normal (Ibid.). The central limit theorem is crucial in statistics as it allows the researcher to make inferences about the population mean without having to know the specific shape of the population distribution (Berenson and Levine 1992). 
Although statisticians generally agree that a sample size of 30 can replicate a population, formulas that are more precise exist to help researchers select appropriate sample sizes. Floro used the Research Methodology Decision Aid computer program to determine his required survey size (Floro 1994). Based on this program, the required sample size for the current Tripler population is 302 . However, a more common formula exists to aid researchers in selecting sample size if certain factors are known (Daniel 1978, Plsek 1994, Cooper and Emory 1995). If one has an estimate of the standard deviation of the mean for population, then the researcher can more accurately estimate the appropriate sample size required given a certain precision level (Cooper and Emory 1995). Methods available to obtain estimates of the mean include conducting a pilot study or previous survey data for the population. The standard deviation of the mean for Floro's study was .658 . The precision level for this study will be .1 with a 95 percent confidence level ( $\mathrm{Z}=1.96)$. The significance level (alpha) is set at .05 .

The minimal sample size (n) required for this study will be:

$$
\begin{aligned}
& \mathrm{n}=\text { Standard Deviation }{ }^{2} /(\text { precision level } / \mathrm{z} \text {-score })^{2} \text { or } \\
& \mathrm{n}=.658^{2} /(.1 / 1.96)^{2}=166.33 \text { or } 167
\end{aligned}
$$

When a population studied is finite, a population correction factor may be appropriate in calculating the required sample size (Cooper and Emory 1995). When the sample size goes above a given percent of the actual population, then application of a population correction factor should be considered. Statisticians disagree over precisely when a population correction factor should be applied. Arguments often range from sample sizes greater than five percent (Cooper and Emory 1995) to greater than ten percent (Plsek 1994) of the actual population. Since the sample size estimated for this 
study falls between this range, it is prudent to apply the population correction factor. Using the method outlined by Cooper and Emory, the calculated sample size required after considering the population correction factor is 158 .

Statistically, a sample size of 158 is sufficiently large enough for the purpose of this study. As this study attempts to replicate Floro's study, we will use the same methodology Floro used to calculate sample size. Considering Floro's methodology, a sample size of 302 will be required. It is noted, however, that this sample size is larger than what more commonly used techniques would require.

The study conducted by Floro used a stratified random sampling technique to measure the employee perceptions at Tripler (Floro 1994). This study replicated his methodology. Specifically, a stratified personnel roster was produced with the stratification based on military verses civilian employees, and by job type. This roster stratified the approximate 2677 employees into the same 14 segments used by Floro in his study.

Floro experienced approximately 65 percent return rate for the survey (Floro 1994). Anticipating this, Floro sent surveys to 18.5 percent of the employees in each of the 14 segments in order to ensure an adequate sample size for to be available for analysis (Ibid.). Replicating this required the selection of 496 survey participant for this study. A computerized random number generator was used to select the required number of participants for this survey from the stratified rosters.

\section{Ethical Concerns}

A local union affiliated with the American Federation of Government Employees represents several categories of employees at Tripler. The survey responses will include 
both demographic data and employee opinions. Unions often object to management collection of such data fearing management reprisals against employees who voice unpopular opinions. Permission was sought and obtained from the local union for surveying bargaining unit employees.

Survey participant confidentiality is an important consideration whenever survey methods are employed. The survey instructions will stress the confidentiality of responses and that no name is required or desired on the completed survey. To ensure confidentiality, no individual surveys will be presented to management, and only consolidated survey results will be presented.

\section{$\underline{\text { Statistical Methods }}$}

Using SPSS, analysis will be made of the sampled population to include descriptive and inferential statistics. SPSS will also be used to make descriptive and inferential analysis of the differences between the 1996 survey responses to the benchmark survey conducted by Floro.

Descriptive statistical analysis will be used to summarize response rates, demographic characteristics, survey means, standard deviations, and other comparative studies. This will allow the ability to compare the responses of the proposed survey to Floro's survey.

Inferential statistics will be used to look for differences between demographic groups on construct scores. Inferential statistic will also test for differences between the proposed survey responses and the responses reported in Floro's study. Student's t-test will be used to test for differences between group means to include gender, military-vs.civilian occupational status, position, pay grade and other categories. A one way analysis 
of variance, or ANOVA, will be used to test for significant differences in measures of central tendency, or means, between groups. Post-hoc analysis will include Tukey's Honestly Significant test, if determined necessary using ANOVA. Cronbach's alpha will be used to conduct a reliability analysis. 


\section{CHAPTER 3}

\section{EXPECTED FINDINGS AND UTILITY OF RESULTS}

The null hypothesis $\left(\mathrm{H}_{\mathrm{o}}\right)$ for this project is that no difference exists between means of the groups being tested. A second $\mathrm{H}_{0}$ is established that no difference exists between means of Floro's survey to those found in the proposed survey. The alternate hypothesis $\left(\mathrm{H}_{\mathrm{ax}}\right)$ is that a difference between means will be found that will enable meaningful analysis of the population at Tripler. Specifically, the alternative hypotheses to be tested are:

$\mathrm{H}_{\mathrm{a1}}$ : Differences exist in variables affecting construct scores. This hypothesis will be used to test whether demographic variables such as position description, sex, and military/civilian status are related to construct mean scores for the tested variables.

$\mathrm{H}_{\mathrm{a} 2}$ : Differences exist in variables related to whether survey was completed in 1994 verses 1996 . This hypothesis will be used to test whether a statistically significant difference exists in tested variables between the 1994 population and the 1996 population of Tripler. This hypothesis will also be used to test for differences in variables between demographic groups in the 1994 survey verses the 1996 survey.

The significance level (alpha) is set a .05 .

\section{Value of Study}

This study will be of direct benefit to the management of Tripler Regional Medical Center. This research hopes to demonstrate a significant difference between the means for the population in the original survey conducted by Floro and this proposed survey. If differences exist, this information can be analyzed to determine the 
effectiveness of TQM implementation as it relates to the impact on organizational culture. This information can be used to target training at specific areas shown deficient, or where lack of progress is evident. This information will also be valuable to the senior leadership at Tripler as they consider organizational strategy and direction. 


\section{CHAPTER 4}

\section{RESULTS}

\section{$\underline{\text { Return Rate }}$}

Of the 496 surveys distributed in this study, 310 surveys were returned. Of the 310 surveys returned, seven were considered unusable for this study due to incomplete responses. This calculates to just over 61 percent response rate or 303 surveys.

Table 1 lists the return rate by occupational category. The highest response rate was "other staff" which includes administrators, chaplains, attorneys, and engineers. The excessively high return rate for this group is most likely due to individuals working in administrative positions but are holding non administrative position classifications on the manning rosters. The second highest responding group was allied health professionals at 82 percent followed by physicians at 74 percent. This was followed by office/clerical staff at 66 percent, registered nurses at 49 percent, and medical technicians at 41 percent. The occupational category with the lowest return rate was the service staff at 30 percent.

Table 1. Sample Demographics and Return Rates

\begin{tabular}{|c|c|c|c|c|c|}
\hline Occupation & Population & Sampled & Returned & $\begin{array}{l}1996 \\
\text { Percent } \\
\text { Returned } \\
\end{array}$ & $\begin{array}{l}1994 \\
\text { Percent } \\
\text { Returned }\end{array}$ \\
\hline Physicians & 304 & 57 & 42 & $74 \%$ & $75 \%$ \\
\hline Registered Nurses & 421 & 78 & 38 & $49 \%$ & $61 \%$ \\
\hline Allied Health & 212 & 39 & 33 & $85 \%$ & $69 \%$ \\
\hline Medical Technicians & 818 & 151 & 62 & $41 \%$ & $51 \%$ \\
\hline Office/Clerical Staff & 556 & 103 & 68 & $66 \%$ & $70 \%$ \\
\hline Service Staff & 270 & 50 & 15 & $30 \%$ & $56 \%$ \\
\hline Administrative Staff & 96 & 18 & 45 & $250 \%$ & $91 \%$ \\
\hline Military & 1382 & 256 & 148 & $58 \%$ & $57 \%$ \\
\hline \multirow[t]{2}{*}{ Civilian } & 1295 & $\underline{240}$ & 155 & $65 \%$ & $73 \%$ \\
\hline & $\overline{2677}$ & 496 & $\overline{303}$ & & \\
\hline
\end{tabular}


In comparing 1994 to 1996 , return rates were identical for the military population at 57 percent. The return rate was nearly identical for physicians, with 1994 to 1996 rates at 75 and 74 percent respectively. In both the 1994 and 1996 surveys, civilian employees returned surveys at a higher rate than military employees did.

\section{Demographic Characteristics}

Table 2 provides a complete listing of the demographic composition of survey respondents. The sample was 51 percent civilian and 49 percent military. Of the sampled military population, 51 percent were officers and 49 percent were enlisted. Males comprised 47 percent of the sample where females made up 53 percent. A majority of the sample respondents indicated they were nonsupervisors, at 64 percent, and supervisors made up 36 percent. Over 43 percent of the sample respondents indicated they have worked at Tripler between 1-3 years, nearly double the next highest response of 4-9 years. Approximately 42 percent of the respondents indicated they had between 1020 years of total federal service, with 4-9 years, at 30 percent, being the second most frequent response.

The demographics of the samples in the two surveys differ in several areas. The overall military population at Tripler dropped by 476 soldiers, from 1858 to 1382 . This reduction in military population was the result of two factors. First, several major functional areas within Tripler in 1994 were no longer part of Tripler in 1996. Two of the major activities no longer part of Tripler are Dental and Veterinary services. A second factor contributing to the reduction in military staffing include the ongoing "downsizing" of the military force structure. 
Table 2. Demographic Characteristics of Survey Respondents $(1996, n=303 ; 1994, n=352)$

\begin{tabular}{|c|c|c|c|c|c|}
\hline & & $\begin{array}{c}1996 \\
\text { Number of } \\
\text { Respondents }\end{array}$ & $\begin{array}{c}1996 \\
\text { Percent of } \\
\text { Total }\end{array}$ & $\begin{array}{c}1994 \\
\text { Number of } \\
\text { Respondents }\end{array}$ & $\begin{array}{c}1994 \\
\text { Percent of } \\
\text { Total }\end{array}$ \\
\hline \multirow[t]{7}{*}{ Occupational Group } & Physician & 42 & $14 \%$ & 55 & $16 \%$ \\
\hline & Registered Nurses & 38 & $13 \%$ & 49 & $14 \%$ \\
\hline & Allied Health Professionals & 33 & $11 \%$ & 40 & $12 \%$ \\
\hline & Med. Technicians & 62 & $21 \%$ & 102 & $29 \%$ \\
\hline & Office/Clerical & 68 & $23 \%$ & 64 & $18 \%$ \\
\hline & Service & 15 & $5 \%$ & 23 & $7 \%$ \\
\hline & Administrative/Other & 45 & $15 \%$ & 10 & $3 \%$ \\
\hline \multirow[t]{2}{*}{ Federal Service Status } & Military & 148 & $49 \%$ & 198 & $56 \%$ \\
\hline & Civilian & 155 & $51 \%$ & 154 & $44 \%$ \\
\hline \multirow[t]{9}{*}{ Military Rank } & PVT-SPC & 17 & $12 \%$ & 39 & $20 \%$ \\
\hline & SGT-SSG & 33 & $22 \%$ & 40 & $20 \%$ \\
\hline & SFC-CSM & 23 & $15 \%$ & 17 & $9 \%$ \\
\hline & WO1-CW5 & 1 & $1 \%$ & 0 & $0 \%$ \\
\hline & 2LT-CPT & 34 & $23 \%$ & 49 & $25 \%$ \\
\hline & MAJ-LTC & 34 & $23 \%$ & 45 & $23 \%$ \\
\hline & COL \& above & 6 & $4 \%$ & 9 & $5 \%$ \\
\hline & Officer & 75 & $51 \%$ & 103 & $52 \%$ \\
\hline & Enlisted & 73 & $49 \%$ & 96 & $48 \%$ \\
\hline \multirow[t]{5}{*}{ Civilian Pay Grade } & WG 01-WG 02 & 2 & $1 \%$ & 2 & $1 \%$ \\
\hline & WG 03-WG 07 & 10 & $6 \%$ & 9 & $6 \%$ \\
\hline & GS 01-GS 05 & 65 & $42 \%$ & 43 & $30 \%$ \\
\hline & GS 05-GS 09 & 42 & $27 \%$ & 54 & $38 \%$ \\
\hline & GS $10 \&$ above & 36 & $23 \%$ & 36 & $25 \%$ \\
\hline \multirow[t]{2}{*}{ Gender } & Male & 143 & $47 \%$ & 182 & $53 \%$ \\
\hline & Female & 160 & $53 \%$ & 161 & $47 \%$ \\
\hline \multirow[t]{2}{*}{ Supervisory Position } & Supervisor & 109 & $36 \%$ & 112 & $32 \%$ \\
\hline & Nonsupervisor & 194 & $64 \%$ & 239 & $68 \%$ \\
\hline Length of Time & $0-11$ Months & 54 & $18 \%$ & 59 & $17 \%$ \\
\hline \multirow[t]{4}{*}{ at Tripler } & $1-3$ Years & 129 & $43 \%$ & 159 & $45 \%$ \\
\hline & 4-9 Years & 65 & $22 \%$ & 72 & $21 \%$ \\
\hline & 10-20 Years & 46 & $15 \%$ & 38 & $11 \%$ \\
\hline & 20 or More & 9 & $3 \%$ & 18 & $5 \%$ \\
\hline Length of Total Federal & $0-11$ Months & 16 & $5 \%$ & 5 & $1 \%$ \\
\hline \multirow{4}{*}{ Service } & 1-3 Years & 36 & $12 \%$ & 55 & $16 \%$ \\
\hline & 4-9 Years & 90 & $30 \%$ & 107 & $30 \%$ \\
\hline & 10-20 Years & 126 & $42 \%$ & 127 & $36 \%$ \\
\hline & 20 or More & 35 & $12 \%$ & 47 & $14 \%$ \\
\hline
\end{tabular}


The shift in population also changed the civilian and military mixture assigned to Tripler. The number of civilian employees assigned to Tripler increased by over 8 percent from 1138 to 1295 . After considering the changes in the military and civilian populations, overall the population assigned to Tripler dropped by almost 11 percent from 2996 to 2677 employees.

A clearer and perhaps more meaningful picture of this population change is reveal when you compare the total employees in each of the occupational categories. In four of the seven categories the population decreased, while it increased in three categories. The allied health, medical technician, physician, and nursing staff decreased by $33,25,22$, and 3 percent respectively. The population of other staff, service staff, and office/clerical staff increased by 66,22 , and 13 percent respectively.

The male to female ratio of survey respondents changed slightly between 1994 and 1996. The ratio of males to females in 1994 was 53 to 47 percent respectively. In 1996, this male to female ratio flip-flopped to 47 to 53 percent respectively. This writer lacked the information required to analyze whether this change was due to a real change in the composition of the workforce or was due to other factors.

The self reported length of time at Tripler and the length of active federal service showed similarities between the 1994 and 1996 surveys. For length of time at Tripler, the mode response for both surveys was between one to three years, comprising 45 and 43 percent of the responses for the 1994 and 1996 surveys respectively. The second most frequent response for both surveys was four to nine years, at 21 and 22 percent for 1994 and 1996 respectively. The third, forth and fifth response choices also matched in both surveys. These responses are consistent with most organizations with military 
populations who move roughly every three years, with some variation. The survey indicated the 1996 population had slightly more time working at Tripler. About 40 percent of the 1996 survey respondents reported four or more years at Tripler, compared to 37 percent in the 1994 survey with four or more years of service at Tripler.

Like the length of time at Tripler, the self reported length of federal service responses in the 1996 survey mirrored the responses found in the 1994 survey. The mode response for the 1996 and 1994 survey was between ten to twenty years of total federal service, with the frequency in the 1996 and 1994 surveys at 42 and 36 percent, respectively. The second most frequent response for length of total federal service in the 1996 and 1994 surveys were between four to nine years, with the frequencies at 30 percent in both surveys. Both surveys indicated that greater than 80 percent of the Tripler population had generally worked in the federal service for four or more years. Approximately one percent of the 1994 population had less than one year of total federal service, with approximately five percent of the 1996 survey participants having less than one year of federal service.

The mean age within the sample of the 1996 survey was 38 years with 69 percent between 29 and 48 years of age. For the 1994 survey, the mean age was 37 years, with 69 percent of the population falling between 30 and 49 years of age. The range of ages for the 1996 survey was from 20 to 68 years of age. The mode for the 1996 survey was 33 years of age. Insufficient data in this area from the 1994 survey prohibits a more detailed analysis in this area. 


\section{Descriptive Statistics}

Using SPSS, mean scores and standard deviation were determined for the survey. Table 3 provides a synopsis of this data. The survey used a five-point scale $(1=$ strongly disagree, $2=$ disagree, $3=$ neither agree nor disagree, $4=$ agree, $5=$ strongly agree). Twentyfive of the 56 survey questions were worded as negative questions, where a low score is viewed as a more positive assessment of climate. In order to aid the reader in interpretation and to mirror the 1994 survey, the ratings for these 25 questions were recoded to reflect a score of " 5 " as being the most positive response.

Mean scores ranged from 2.34 to 3.92 . The range of the mean scores for the 1994 survey was from 2.34 to 3.88 . The survey mean for the 56 questions was 3.15 . Thirtyfive of the 56 means scored above 3.0, with 21 scoring below 3.0. In the 1994 survey, only 30 of the 56 means score above 3.0 . The highest scoring item was " $T Q M$ is important to me" with a mean of 3.92. The lowest scoring item was "Not enough reward and recognition for good work" at 2.34. This item was also the lowest scoring question in the 1994 survey. The standard deviation for the 1996 survey ranged from .79 to 1.31 . The mean standard deviation for the survey was 1.09 . The range of standard deviation in the 1994 survey was from .85 to 1.30 . Floro reported a mean standard deviation of approximately 1.0 .

Ten of the 56 questions on the 1996 survey score above 3.50 . This compares to seven of the ten questions scoring above 3.50 in the 1994 survey. The ten questions scoring above 3.50 in the 1996 survey are, TQM is important to me (3.92), High performance standards at TAMC (3.79), I know a lot about TQM (3.78), I understand my 
Table 3. Mean and Standard Deviation for 1996 and 1994 Survey

Table 3. Mean and Standard Deviation for 1996 and 1994 Survey

\begin{tabular}{cccc}
1996 & 1996 & 1994 & 1994 \\
Mean & Std. Dev. & Mean & Std. Dev. \\
\hline
\end{tabular}

\section{STRUCTURE:}

1. Jobs are clearly defined and logically structured

$\begin{array}{llll}3.45 & 1.01 & 3.41 & 1.08 \\ 3.14 & 1.31 & 3.12 & 1.30 \\ 3.53 & 1.08 & 3.53 & 1.08 \\ 2.74 & 1.07 & 2.71 & 1.12 \\ 2.84 & 1.16 & 2.78 & 1.08 \\ 2.55 & 1.16 & 2.78 & 1.19 \\ 3.47 & 1.21 & 3.48 & 1.20 \\ 2.98 & 1.09 & 2.86 & 1.06\end{array}$

\section{RESPONSIBILITY:}

* 9. Individual judgement is not relied upon

10. If you have the right approach, just go ahead

11. Supervisors set guidelines and allow subordinates to take responsibility

* 12. To get ahead at TAMC you must stick your neck out

* 13. People should solve problems by themselves

* 14. Lots of excuses when mistakes are made

* 15. Too many people are unwilling to take responsibility

$\begin{array}{llll}3.02 & 1.10 & 3.01 & 1.09 \\ 2.58 & 0.93 & 2.55 & 0.97 \\ 3.13 & 1.07 & 3.16 & 1.04 \\ 3.10 & 1.07 & 3.15 & 1.03 \\ 3.31 & 1.03 & 3.39 & 0.99 \\ 2.81 & 1.14 & 2.90 & 1.14 \\ 2.81 & 1.23 & 2.88 & 1.20\end{array}$

\section{REWARD:}

16. The best rise to the top in our promotion system

17. Rewards outweigh threats and criticisms

18. Rewards and promotion is linked to excellence in job performance

* 19. Not enough reward and recognition for good work

* 20. Lots of criticism at TAMC

* 21. Make a mistake and you will be punished

RISK:

* 22. We get ahead by playing it slow, safe, sure

$\begin{array}{llll}3.11 & 2.55 & 2.80 & 0.89 \\ 3.06 & 0.79 & 2.95 & 0.90 \\ 3.05 & 0.91 & 2.93 & 0.93 \\ 3.39 & 0.93 & 3.22 & 0.99\end{array}$

* 24. Decision making is too cautious

25. Management will take a chance on a good idea

\section{WARMTH:}

26. A friendly atmosphere prevails at TAMC

27. Relaxed, easy going climate at TAMC

* 28. It is hard to get to know people at TAMC

* 29. At TAMC people are cool and aloof 
Table 3. (Continued) Mean and Standard Deviation for 1996 and 1994 Survey

\begin{tabular}{|c|c|c|c|c|}
\hline . & $\begin{array}{l}1996 \\
\text { Mean }\end{array}$ & $\begin{array}{c}1996 \\
\text { Std. Dev. }\end{array}$ & $\begin{array}{l}1994 \\
\text { Mean }\end{array}$ & $\begin{array}{c}1994 \\
\text { Std. Dev. }\end{array}$ \\
\hline \multicolumn{5}{|l|}{ SUPPORT: } \\
\hline * 31. Not much sympathy if you make a mistake & 3.03 & 0.98 & 2.98 & 0.99 \\
\hline 32. Management talks with you about career aspirations & 2.92 & 1.18 & 2.84 & 1.17 \\
\hline * 33. People don't trust each other at TAMC & 3.08 & 1.12 & 3.08 & 1.02 \\
\hline 34. Management philosophy values how employee's feel & 2.95 & 1.03 & 2.92 & 1.04 \\
\hline 35. Employee's can count on management support in difficult assignments & 3.58 & 1.04 & 3.55 & 1.06 \\
\hline \multicolumn{5}{|l|}{ STANDARDS: } \\
\hline 36. High performance standards are set at TAMC & 3.79 & 0.94 & 3.68 & 0.97 \\
\hline 37. Management believes that no job is so well done that it couldn't be done better & 3.49 & 0.99 & 3.31 & 0.95 \\
\hline 38. Pressure exists to continually improve personal and group performance & 3.44 & 1.02 & 3.29 & 1.02 \\
\hline 39. Management believes that if people are happy, productivity will take care of itself & 2.92 & 1.10 & 2.98 & 1.04 \\
\hline * 40 . To get ahead it is more important to get along than to be a high producer & 2.84 & 1.06 & 2.74 & 1.05 \\
\hline * 41. At TAMC people don't take pride in their performance & 3.38 & 1.14 & 3.33 & 1.11 \\
\hline \multicolumn{5}{|l|}{ CONFLICT: } \\
\hline * 42. The best way to make a good impression is to avoid arguments and disagreements & 2.63 & 1.10 & 2.56 & 1.08 \\
\hline 43. Management feels conflict between competing departments can be healthy & 2.73 & 0.83 & 2.69 & 0.85 \\
\hline 44. Employees are encouraged to speak their minds even if disagreeing & 2.87 & 1.13 & 2.86 & 1.10 \\
\hline * 45. At meetings the goal is to make decisions smoothly and quickly & 2.81 & 0.96 & 2.89 & 0.96 \\
\hline \multicolumn{5}{|l|}{ INDENTIFY: } \\
\hline 46. People are proud to belong to TAMC & 3.48 & 0.99 & 3.42 & 0.95 \\
\hline 47. I am a member of a well functioning team & 3.42 & 1.11 & 3.49 & 1.05 \\
\hline * 48. People are not loyal to TAMC & 3.34 & 1.07 & 3.25 & 1.04 \\
\hline * 49. People at TAMC just look out for themselves & 2.79 & 1.17 & 2.76 & 1.14 \\
\hline \multicolumn{5}{|l|}{ TQM: } \\
\hline 50. Leadership is actively involved in promoting TQM & 3.52 & 0.91 & 3.31 & 0.98 \\
\hline 51. Senior management action shows strong commitment to TQM & 3.42 & 1.02 & 3.28 & 1.02 \\
\hline 52. My supervisor is strongly committed to TQM & 3.53 & 1.05 & 3.34 & 1.09 \\
\hline 53. TQM is important to me & 3.92 & 0.95 & 3.88 & 0.91 \\
\hline 54. I understand my role in contributing to TQM goals & 3.77 & 0.95 & 3.72 & 0.99 \\
\hline 55. I understand how TQM is being implemented at TAMC & 3.36 & 1.02 & 3.15 & 1.07 \\
\hline * 56. I don't know much about TQM & $\underline{3.78}$ & 1.15 & $\underline{3.72}$ & 1.13 \\
\hline AVERAGE MEAN SCORE: & 3.15 & & 3.10 & \\
\hline
\end{tabular}

(a) All scores have been recoded to reflect " 5 " as being the most positive rating. The recoded questions are indicated with *.

(b) Variable rated on a 5-point scale: 1=strongly disagree; 2=disagree; 3=neither agree nor disagree; 4=agree; 5=strongly agree.

(c) Survey questions are in abbreviated form on this table. 
role in TQM (3.77), A friendly atmosphere exists at TAMC (3.64), Employee's can count on management support (3.54), Policies are clearly explained (3.53), Ease of getting to know people at TAMC (3.53), My supervisor is strongly committed to TQM(3.53), and Leadership is actively involved in promoting TQM(3.52). All of the seven questions scoring above 3.50 on the 1994 survey also scored above 3.50 on the 1996 survey. The three question scoring above 3.50 on the 1996 survey but not on the 1994 survey are Leadership is actively involved in promoting TQM, My supervisor is strongly committed to TQM, and Ease of getting to know people at TAMC.

In the 1994 and 1996 survey, two questions scored below 2.50. In both the 1994 and in the 1996 survey, the same two questions scoring below 2.50 . These two questions were Not enough reward and recognition (2.34) and The best rise to the top in our promotion system (2.44).

The construct variable mean scores are reflected in table 4. The TQM construct

Table 4. Construct Variable Means Comparison

\begin{tabular}{lcccc} 
Construct Variable (a) & $\begin{array}{c}1996 \\
\text { Mean }\end{array}$ & $\begin{array}{c}1996 \\
\text { Std Deviation }\end{array}$ & $\begin{array}{c}1994 \\
\text { Mean }\end{array}$ & $\begin{array}{c}1994 \\
\text { Std Deviation }\end{array}$ \\
\hline TQM (7) & 3.62 & 0.66 & 3.49 & 0.62 \\
Warmth (5) & 3.39 & 0.82 & 3.35 & 0.77 \\
Standards (5) & 3.31 & 0.59 & 3.22 & 0.56 \\
Identify (4) & 3.26 & 0.90 & 3.23 & 0.86 \\
Risk (4) & 3.15 & 0.78 & 2.97 & 0.57 \\
Support( 5) & 3.11 & 0.81 & 3.15 & 0.75 \\
Structure (8) & 3.09 & 0.70 & 3.08 & 0.65 \\
Responsibility (7) & 2.96 & 0.54 & 3.01 & 0.49 \\
Conflict (4) & 2.76 & 0.54 & 2.75 & 0.54 \\
Reward (6) & 2.73 & 0.78. & 2.70 & 0.77
\end{tabular}

(a) The number of survey questions within the construct

(b) Uses 5-point Likert scale: $1=$ strongly disagree, 5=strongly agree 
was the only construct of the ten scoring above 3.50 , at 3.62. No construct scored below 2.50. The constructs Warmth (3.39), Standards (3.31), Identity (3.26), Risk (3.15), Support (3.11), and Structure (3.09) scored above 3.0. Scoring below 3.0 on the 1996 survey were Responsibility (2.96), Conflict (2.76), and Reward (2.72). In both the 1994 and the 1996 survey, seven of ten constructs scored above 3.0. However, during the 1994 survey, Responsibility scored above 3.0 and Risk scored below 3.0, a reverse of what was found in the 1996 survey. The standard deviation for the 1996 survey ranged from .54 to .90 , and from .49 to .86 on the 1994 survey.

Using Cronbach's Alpha, a reliability analysis was conducted to test the internal consistency of the constructs. The results of this analysis are found in table 5 . The

Table 5. Alpha Coefficient (a)

\begin{tabular}{lcc} 
Construct Variable (a) & $\begin{array}{c}1996 \\
\text { alpha }\end{array}$ & $\begin{array}{c}1994 \\
\text { alpha }\end{array}$ \\
\hline Coefficient & $\begin{array}{c}\text { Coefficient } \\
\text { Identify }\end{array}$ & \\
Warmth & 0.85 & 0.84 \\
Support & 0.81 & 0.77 \\
Reward & 0.81 & 0.74 \\
TQM & 0.77 & 0.77 \\
Structure & 0.77 & 0.75 \\
Standards & 0.76 & 0.71 \\
Responsibility & 0.57 & 0.53 \\
Risk & 0.50 & 0.36 \\
Conflict & 0.43 & 0.51 \\
& 0.16 & 0.19
\end{tabular}

(a) Using Cronbach's alpha coefficient

(b) Scores above .70 are considered highly reliable Scores between .50 and .69 are considered acceptable Scores below .50 have doubtful reliability'.

results of the 1996 survey closely match the results of the 1994 survey. In both the 1994 and 1996 surveys, the constructs Structure, Warmth, Support, TQM, Reward, and Identify 
scored above .70 , which is generally considered highly reliable. On both surveys, the Conflict construct showed poor internal consistency.

\section{Inferential Statistics}

Using SPSS, a one-way analysis of variance (ANOVA) was conducted for the ten construct variables. This test revealed a difference in the population $(p \leq .05)$ using demographic variables. The demographic variables revealing a significant difference in the population include occupation, and whether an individual was an officer, enlisted or civilian employee, among others.

The one-way ANOVA showed a significant difference in seven of the ten construct scores when using occupation as the demographic variable. The $\underline{F}$ values for the constructs showing a statistical significance are Warmth $\underline{\mathrm{F}}(6,296)=3.94, \mathrm{p}=.001$; Support $\underline{\mathrm{F}}(6,296)=3.88, \mathrm{p}=.001 ;$ Standard $\underline{\mathrm{F}}(6,296)=3.05, \mathrm{p}=.007 ;$ Structure $\underline{\mathrm{F}}(6$, 296) $=2.97, \mathrm{p}=.008 ;$ Identity $\underline{\mathrm{F}}(6,296)=2.44, \mathrm{p}=.025 ;$ Responsibility $\underline{\mathrm{F}}(6,296)=2.21$, $\mathrm{p}=.042 ;$ and Reward $\underline{\mathrm{F}}(6,296)=2.14, \mathrm{p}=.049$. This compares to only two of the ten constructs showing a significant difference in the 1994 survey. The two significant constructs in the 1994 survey were Risk $\underline{\mathrm{F}}(6,336)=2.43, \mathrm{p}=.026$, and Warmth $\underline{\mathrm{F}}(6$, $336)=3.67, \mathrm{p}=.002$

As in the 1994 survey, Tukey's Honestly Significant Difference (HSD) test was used for post-hoc analysis. Tukey's HSD was used to make multiple comparisons for the constructs identified as being significant in the one-way ANOVA. Table 6 shows the results of this analysis. The demographic variables of physicians and service workers proved to demonstrate the most differences within the occupational grouping. 
Table 6. Differences Among Occupational Categories.

\begin{tabular}{lcccccccc}
\hline Occupational Category & \multicolumn{7}{c}{ Number of Differences for Listed Construct(a) } \\
\hline & Warmth & Support & Structure & Standards & Reward & Responsibility & Identify & Differences \\
\hline Physicians & 3 & 2 & 1 & 1 & 1 & 0 & 0 & 8 \\
Registered Nurses & 0 & 0 & 0 & 0 & 0 & 0 & 0 & 0 \\
Allied Health Professionals & 0 & 0 & 1 & 0 & 0 & 0 & 0 & 1 \\
Medical Technicians & 1 & 0 & 1 & 0 & 0 & 0 & 0 & 2 \\
Office/Clerical & 1 & 1 & 0 & 0 & 0 & 0 & 0 & 2 \\
Service Workers & 1 & 2 & 4 & 2 & 1 & 0 & 0 & 10 \\
Other & 0 & 1 & 1 & 1 & 0 & 0 & 0 & 3
\end{tabular}

(a) Using Tukey's Honestly Significant Difference test

A one-way analysis was conducted on each of the constructs testing for difference in the population using the demographic variable of whether an individual was an officer, enlisted or civilian employee. Significant differences were found in six of the ten constructs. The $\underline{\mathrm{F}}$ values for the six constructs are as follows: Warmth $\underline{\mathrm{F}}(2,300)=10.19$, $\mathrm{p}=.000 ;$ Support $\mathrm{E}(2,300)=7.94, \mathrm{p}=.000 ;$ Identify $\underline{\mathrm{F}}(2,300)=7.12, \mathrm{p}=.001$;

Standard $\underline{\mathrm{F}}(2,300)=4.38, \mathrm{p}=.013 ;$ Reward $\underline{\mathrm{F}}(2,300)=3.48, \mathrm{p}=.032 ;$ and Structure $\underline{\mathrm{F}}$ $(2,300)=3.38, \mathrm{p}=.035$.

On the post-hoc analysis using Tukey's HSD, differences were found as listed in table 7. Differences were found in six of the constructs. Officer and enlisted demographic variables exhibited significant differences in each of the six tested constructs. The civilian demographic variable was found significant in only three of the six variables.

No significant difference in construct scores was found using one-way ANOVA in differences for gender, or supervisory status. This differs from Floro's study, which found significant differences using these demographic variables. Floro found significant 
Table 7. Differences Among Service Status.

\begin{tabular}{lccccccc}
\hline $\begin{array}{l}\text { Service } \\
\text { Status }\end{array}$ & Wumber of Differences for Listed Construct(a) \\
\hline & Warmth & Support & Structure & Standards Reward & Identify & $\begin{array}{c}\text { Total } \\
\text { Differences }\end{array}$ \\
\hline Enlisted & 1 & 1 & 1 & 1 & 1 & 1 & 6 \\
Officer & 2 & 2 & 1 & 2 & 1 & 1 & 9 \\
Civilian & 1 & 1 & 0 & 1 & 0 & 0 & 3
\end{tabular}

(a) Using Tukey's Honestly Significant Difference test

differences in constructs Structure, Warmth and Identify using gender. Floro also found a significant difference in means in the Conflict construct using supervisory status.

In both the 1996 and the 1994 study, no significant difference was found in construct scores with the demographic variables length of active federal service or length of time at Tripler.

In the 1996 survey, age was found to show a statistically significant difference in one of the ten construct scores. Using one-way ANOVA, Support was significant at $\underline{F}$ $(1,301)=4.91, \mathrm{p}=.027$

In addition to testing for differences in construct score means, test for differences in mean scores for each of the 56 survey questions was also conducted. Using one-way ANOVA, analysis of difference in means of the 56 questions using demographic variables of occupation and for enlisted, officer, or civilian status was conducted.

Appendix 2 lists results of the one-way ANOVA testing for differences in mean scores for the 56 questions using the demographic variable occupation. The one-way ANOVA test found statistically significant differences in 17 of the 56 questions. 
Appendix 3 lists results of the one-way ANOVA testing for differences in mean scores for the 56 questions using the demographic variable of officer, enlisted, or civilian status. The one-way ANOVA test found statistically significant differences in 25 of the 56 questions. 


\section{CHAPTER 5}

\section{DISCUSSION}

As stated before, the cultural assessment survey is an attempt to measure the attitudes, perceptions and beliefs of the staff as it pertains to working at Tripler. As such, this survey is a measure of satisfaction of the work and social environment at Tripler. If a difference in satisfaction can be found based on demographic variables, then actions can be taken to discover the nature behind these differences. One can look for what is being done right in groups with high satisfaction in order to apply those tools to bring up the satisfaction in other groups. By discovering demographic groups with low satisfaction, the researcher can look at factors influencing their low satisfaction. Then, action that is more appropriate can be taken to improve satisfaction in those groups.

Inferential statistics showed that certain demographic variables within the population had statistically significant differences. This knowledge allows the researcher to use this information to their advantage when trying to make sense out of the volumes

of information made available from research. Knowledge of which specific variables in the population have predictive value allows the researcher to focus their efforts to make their study of value to management.

Inferential statistics applied to the cultural assessment survey showed predictive value in numerous demographic variables. However, two demographic variables were found most predictive of the attitudes, perceptions and beliefs of the staff at Tripler. These demographic variables were occupational status and service status. Service status is whether one was an officer, enlisted, or civilian employee. 


\section{Occupational Status and Satisfaction}

Mean construct scores were graphed for each of the six occupational categories for comparison. Comparisons in mean construct scores were also made between occupational categories to assess change in the population between the 1994 and the 1996 survey. Appendix 4 provides an in-depth review of these graphs.

Inferential statistic showed that physicians and service workers as having the most significant difference within the occupational grouping. The difference in mean construct scores between the 1994 and 1996 survey for physicians are shown in Appendix 4, chart 1. Only the seven constructs testing as highly reliable using Cronbach's alpha are used for this comparison. The chart shows an increase in mean response scores between 1994 and 1996 in each of the seven constructs. The physician subcategory of the occupational demographic variable showed the largest increase in satisfaction of the seven occupations.

Service workers showed the most significant decline in mean construct scores between 1994 and 1996. Chart 2 in Appendix 4 shows service worker responses. Only the seven construct scores testing as reliable using Cronbach's alpha are used. The chart shows that mean construct scores dropped between 1994 and 1996 in each of the seven

constructs. Service workers also showed the greatest average decrease in mean construct scores of the seven occupations in the occupational demographic variable.

\section{$\frac{\text { Service Status and Satisfaction }}{r}$}

Differences were compared using graphs for enlisted, officer and civilian demographic variables. Unfortunately, a lack of the information required from the 1994 survey makes it impossible to make comparisons between 1994 and 1996. However, a 
comparison of differences using the variables in the 1996 survey provides useful insights into the attitudes and perceptions of the current population of Tripler. Included in Appendix 4 are selected charts comparing the enlisted, officer and civilian employees within the Department of Nursing. This study showed that the attitude and perceptions of the enlisted population lagged behind the attitude and perceptions of the officer and civilian workforce.

\section{An Analysis of Associated Causes in Differences in the Population}

As stated earlier, results showed significant differences exist in the population working at Tripler. Officers, and physicians in particular, showed the highest satisfaction. Physicians showed the most improvement in satisfaction from the 1994 survey. Several factors can be identified which may help explain these differences.

Tripler has been involved in extensive TQM training over the last two years. The primary recipients of this training have been the officer personnel. The physician population has been extensively trained in TQM during this time. Only recently has this training been made extensively available to the general population at Tripler.

Another factor that potentially influenced the improvement in satisfaction in officers and physicians was the change in several key leaders at Tripler. The assignment of a new commanding general (CG) at Tripler approximately eight months before this survey may have influenced satisfaction. The new CG's leadership philosophy differs greatly from the previous CG. The current philosophy places great emphasis on values associated with TQM. 


\section{$\underline{\text { Reward Construct }}$}

In both the 1994 and the 1996 survey, the reward construct scored the lowest in overall satisfaction. The reward construct scored 2.70 in 1994 and 2.73 in 1996, using a 5-point Likert scale measurement. No positive response from any demographic group was found in any of the questions in the reward construct.

All demographic groups disagreed with the statement (question 16) that "our promotion system allows the best employees to get promoted. No demographic group associated excellent performance with individual recognition (question 18). All demographic groups tended to agree with the statement that not enough reward and recognition is given at Tripler for doing good work (question 19). Being a service worker, enlisted, or an office or clerical worker predicts a lower score on construct and question means. 


\section{CHAPTER 6}

\section{RECOMMENDATIONS AND CONCLUSION}

Many of the recommendations cited below have already been accomplished at Tripler. These changes were enacted following the presentation of these findings to the Process Improvement Committee (PIC) and to the human resource management functional management team. The Department of Nursing has also taken great interest in using these findings to develop internal actions to improve satisfaction.

\section{Recommendations to the PIC}

In a formal presentation to the PIC at Tripler, this researcher made several specific recommendations regarding these findings. The following outlines these recommendations.

The human resource management functional management team should study the formal and informal reward systems at Tripler. This study should include the use of focus groups comprised of a cross section of employees at Tripler to probe problems in the formal and informal reward systems. Special efforts should be made to include those demographic groups identified as being particularly low scoring in this construct. This focus group should include a trained facilitator to assist in this study. Tripler has several facilitators professionally trained at the Juran Institute of Training in Chicago. The focus group should help to identify specific problems and formulate solutions to be implemented at Tripler. The human resource management team should be given a specific timeframe for studying and implementing solutions to this issue. 
The Quality Services Division, who is responsible for the training and education of the staff, should expand its TQM training program to include all employees at Tripler. Departments and sections should be encouraged and held accountable for developing all employees within their section.

This study found strong positive attitudes and perceptions relating to $T Q M$ (3.6 on a five-point scale) and Warmth (3.4 on a five-point scale). All demographic groups expressed satisfaction in $T Q M$. Warmth relates to the attitude and feeling that Tripler is a good place to work and that employees like their fellow workers. This writer recommended that improvement efforts should attempt to capitalize on these strong areas. By allowing employees to become involved in improvement efforts using TQM methods, Tripler is afforded the greatest opportunity to for success.

This writer also recommended to the PIC that the managers and employees be made aware that demographic differences exist in employee satisfaction. It is of particular importance that the leadership and managers at Tripler be made aware of these differences. Most of the leadership at Tripler falls in the highest scoring demographic group in this survey. These leaders may not be aware that other demographic groups feel differently than the demographic group they most closely relate to. To aid in this education effort, this writer has made numerous command and department level presentations and is developing a storyboard on this project to be place in the dinning facility.

The final recommendation to the PIC was that this study be repeated in 6-12 months. This researcher also recommended that a program be initiated to systematically assess the satisfaction of the employees at Tripler. 
Many of these recommendations have already been widely implemented at Tripler. The Quality Services.Division has developed and currently teaches over seven TQM related courses. These courses have been made available to all employees at Tripler. The Quality Services Division is actively marketing these courses, to include an intranet homepage, the use of electronic mail advertisements, professionally produced brochures, and the use of command emphasis.

The Department of Surgery has recently brought in outside consultants to assist in conducting focus groups, front line training programs, and has reworked it's reward program. The Department of Nursing has taken great interest in presenting the findings of this study to their employees. Three formal presentations of these findings have been made to Department of Nursing staff. The leadership in the Department of Nursing is using the knowledge of these findings to help focus their internal efforts for improvement.

\section{The Survey Instrument}

The modified Litwin-Stringer survey proved again to have generally good internal reliability when measured using Cronbach's alpha. The Conflict construct, however, has shown poor reliability in both the 1994 and 1996 surveys (alpha at .19 and .16, respectively). Researchers wishing to use this survey may wish to modify this construct. Two other constructs, Risk and Responsibility have tended to show marginal internal reliability at Tripler.

This survey consists of 56 questions, which could prove logistically difficult for anything other than academic research. If a systematic assessment of satisfaction were to 
be enacted, another survey instrument should be considered, or further modifications should be made to the Litwin-Stringer survey to make the instrument more user friendly.

\section{Conclusions}

Tripler has the opportunity to make significant improvements in the satisfaction of its employees. Abundant employee training opportunities exist, coupled with a strong commitment from the senior leadership at Tripler to make a change for the better.

There is a correlation between the quality training efforts and increased staff satisfaction. With the planned expansion of these efforts to include all employees at Tripler, this organization has the opportunity to enable a more positive work environment for all employees.

The Total Quality philosophy and efforts at Tripler has already begun to make a difference in many areas. Quality was a critical factor for success in the recent Joint Commission Accreditation inspection, where Tripler scored 99 out of a possible 100, the highest score ever achieved by a Department of Defense hospital at the time. The Tripler quality program was singled out in the Joint Commission's book, Doing the Right Things Right, published in 1997. Tripler was named as one of the seven hospitals worthy of emulating. This book uses Tripler as a case study exploring a health organization "that is doing things right."

If the effort to reach and train all employees at Tripler succeed, Tripler should see a rise in employee satisfaction comparable to the level of increase found in the officer and physician employee groups. Tripler is an organization doing the right things right.

Further research into changes in satisfaction promise to be interesting and fruitful. 
APPENDIX 1

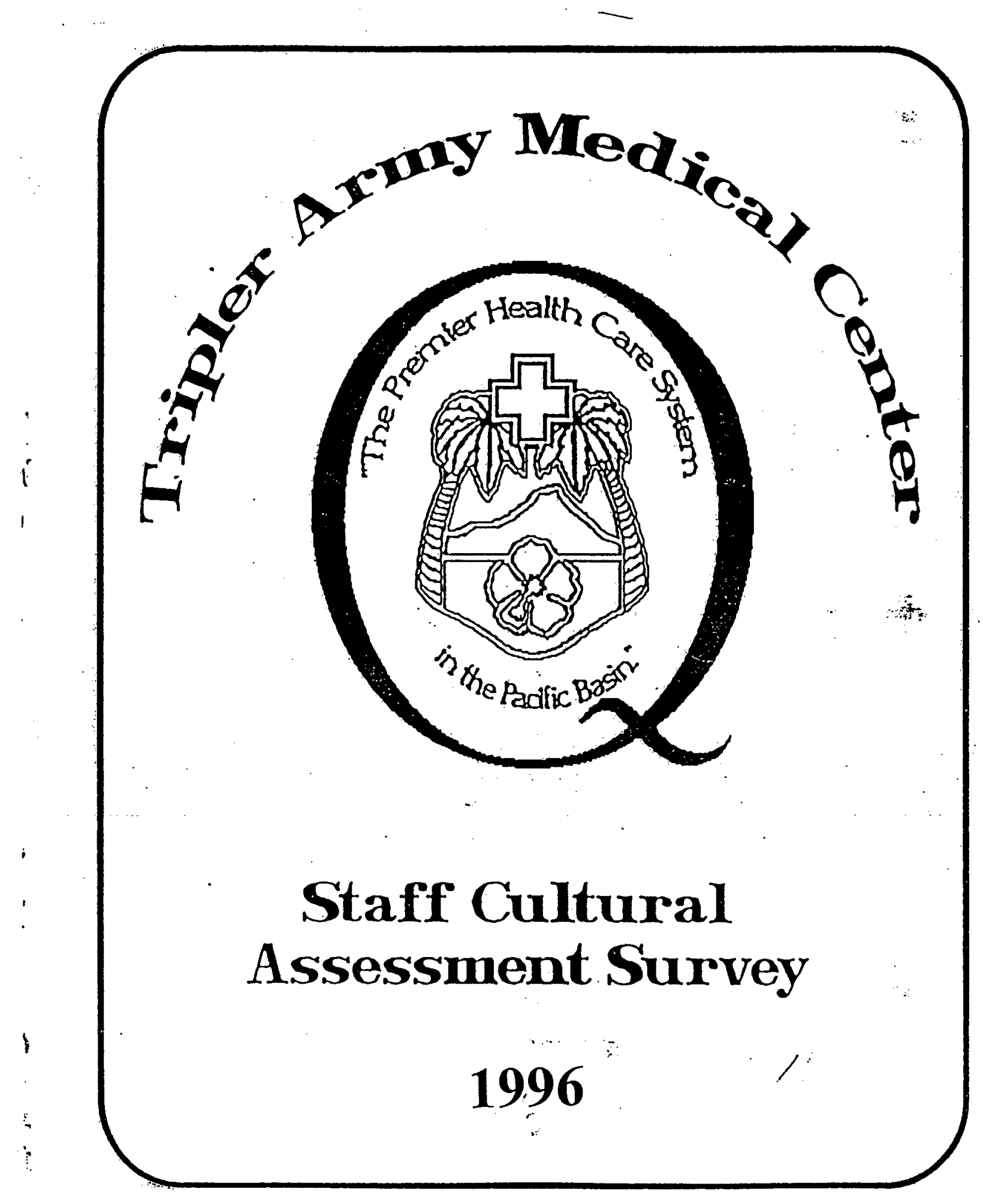




\section{Instructions}

The statements in this survey ask you how you feel about the work conditions in your organization; that is, your overall impression of how things are in your organization. Indicate your answer by circling the ONE number which best represents how you feel about the particular statement. Please answer all questions.

\section{THERE ARE NO RIGHT OR WRONG ANSWERS -- THE ONLY REAL ANSWER IS YOUR HONEST OPINION.}

Use the following definitions when answering the questions in the survey:

Organization - the highest level of Tripler for which you feel you have accurate information; typically one or two levels above your own.

Management - refers to those individuals that provide supervision and/or leadership to you.

Supervisor - refers to your immediate supervisor. If you work in more than one department/unit, refer to the supervisor for the area where you work the
most.

Do not write your name on this survey.

Your individual response will be kept completely confidential. Your responses will be combined with responses gathered from throughout the hospital. Only summary reports will be presented to the leadership of Tripler.

When you have completed the survey, place it in the envelope provided, and return the sealed envelope through the distribution system.

Thank You for Sharing Xour Opinions 


\section{TRIPLER ARMY MEDICAL CENTER CULTURAL ASSESSMENT SURVEY}

DIRECTIONS: After reading each statement use the following response scale and circle the ONE number that accurately describes the degree to which the following statements reflect your personal feeling about Tripler.

I=Strongly Disugrec; 2=Dishgrec; 3eNeliher agrec or disagrec; 4=Agrec; 5=Strongly Agrec.

\section{Structure:}

I. The jobs in this organization are clearly defined and logically structured.

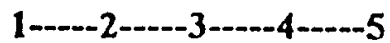

2. In this organization it is sometimes unclear who has the formal authority.

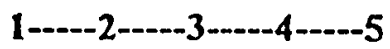

3. The policies and organizational structure of your organization have been clearly explained.

4. Red-tape is kept to a minimum in this organization.

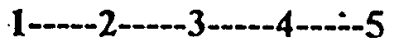

5. Excessive rules, administrative details, and red-

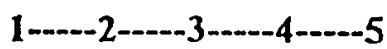
tape make it difficult for new and original ideas to receive consideration.

6. Our productivity sometimes suffers from lack of organization and planning.

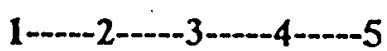

7. In some of the projects l've participated in, I haven't been sure exactly who my boss was.

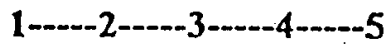

8. Our management isn't so concerned about formal<smiles>[3H][Z]S[As]S</smiles>
organization and authority, but concentrates instead on getting the right people together to do the job. 
$1=$ Strongly Disagrec; $2=$ Disagrce; $3=$ Neiflicr agrec or disagrce; 4=Agrce; 5=Strongly Agrec.

\section{Responsibility:}

9. We don't rely too heavily on individual judgement

$1----2-----3----4-----5$

in this organization; almost everything is doublechecked.

10. Around here management resents your cliecking

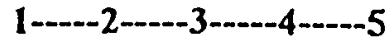
everything with them; if you think you've got the right approach you just go ahead.

11. Supervision in this organization is mainly a<smiles>[3H][Z]S[As]S</smiles>
matter of setting guidelines for your subordinates; you let them take responsibility.

12. You won't get ahead in this organization unless you stick your neck out and try things on your own sometimes.

13. Our philosophy emphasizes that people should solve their problems by themselves.

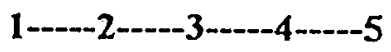

14. There are lots of excuses when someone makes a mistake.

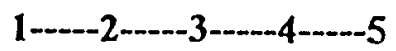

15. One of the problems in this organization is that individuals won't take responsibility.

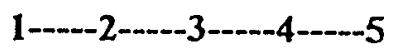

\section{Reward:}

16. We have a promotion system that helps the best individual to rise to the top.

17. In this organization the rewards and encouragements you get usually outweigh the threats and criticism.

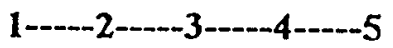

18. In this organization people are rewarded in $1----2-\cdots---3----4-----5$ proportion to the excellence of their job performance. 
L=Strongly Disagrce; 2=Disagrec; $3=$ Nelther agrce or disagrec; 4=Agrec; 5=Strongly Agrec.

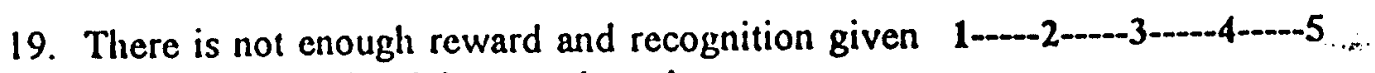
to this organization for doing good work.

20. There is lots of criticism in this organization.

$1----2-\cdots---3----4-----5$

21. If you make a mistake in this organization, you

$1----2----3-----4-----5$ will be punished.

\section{Risk:}

22. The philosophy of our management is that in the

$1----2-----3----4-----5$ long run we get ahead fastest by playing it slow, safe, and sure.

23. Our organization has been built up by taking

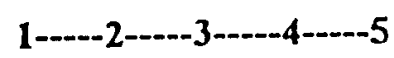
calculated risks at the right time.

24. Decision making in this organization is too $1----2-----3-----4-----5$ cautious for maximum effectiveness.

25. Our management is willing to take a chance on a $1----2---3----4----5$ good idea.

\section{Warmth:}

26. A friendly atmosphere prevails among the people in this organization.

27. This organization is characterized by a relaxed, easy-going working climate.

28. It's very hard to get to know people in this

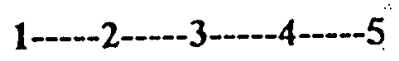
organization.

29. People in this organization tend to be cool and 1----2------------5 aloof towards each other. 
I=Strongly Disagrec; $2=$ Disagrce; $3=$ Nelther agrec or disagrce; $4=\Lambda$ grec; $5=S$ trongly Agrec.

30. There is warmth in the relationship between

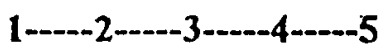

management and workers in this organization.

\section{Support:}

31. You don't receive much sympathy from higher

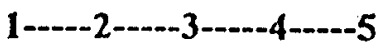
management in this organization if you make a mistake.

32. Management makes an effort to talk with you about your career aspirations.

33. People in this organization don't really trust each $1----2-\cdots--3-\cdots---4----5$ other.

34. The philosophy of our management emphasizes the human factor; how people feel, etc.

35. When I am on a difficult assignment, I can 1-----2-----3-----4------5 usually count on getting assistance from my supervisor and co-workers.

\section{Standards:}

36. In this organization, we set very high standards for performance.

37. Our management believes that no job is so well done that it couldn't be done better.

38. Around here there is a feeling of pressure to continually improve our personal and group performance.

39. Management believes that if the people are $1-----2-----3-----4-\cdots---5$ happy, productivity will take care of itself.
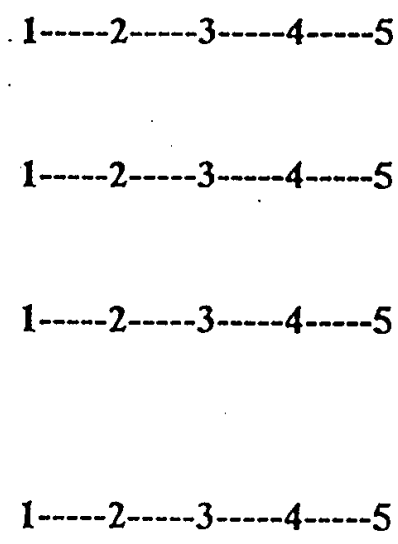
1=Strongly Dlsagrec; 2=Disagrec; 3=Nelther agrec or disagrce; $4=$ Agrec; 5-Strongly Agrec.

40. To get ahead in this organization, it's more

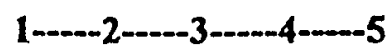
important to get along than it is to be a high producer.

41. In this organization, people don't seem to take $1-----2-----3-----4-----5$ pride in their performance.

\section{Conflict:}

42. The best way to make a good impression around

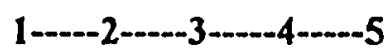
here is to avoid arguments and disagreements.

43. The attitude of our management is that conflict

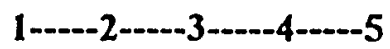
between competing departments and individuals can be healthy.

44. We are encouraged to speak our minds, even if it means disagreeing with our superiors.

45. In management meetings, the goal is to arrive at<smiles>[3H][CH]S[AsH][SiH3]</smiles>
a decision as smoothly and quickly as possible.

\section{Identify:}

46. People are proud of belonging to this organization.

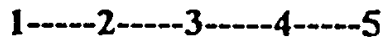

47. I feel that I am a member of a well functioning team.

48. As far as I can see, there is not much personal loyalty to the organization.

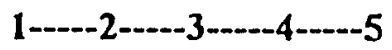

49. In this organization people primarily look out for their own interests.
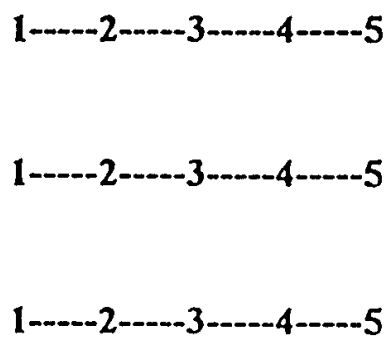


\section{Total Quality Management (TQM):}

50. The overall leadership of Tripler is actively $1----2-----3-----4--\cdots--5$ involved in promoting TQM throughout your facility.

51. The actions and behaviors of senior management $1-\cdots--2-\cdots--3--\cdots------5$ suggest a genuinely strong commitment to TQM.

52. The actions and behaviors of your immediate 1-----2-----3-----4-----5 supervisor suggest a genuinely strong commitment to TQM.

53. TQM is important to you.<smiles>[3H][CH][AsH][AsH][3H]</smiles>

54. You understand your role in contributing to the TQM goals of your organization.

55. You understand how TQM is being implemented at Tripler.

56. You do not know what TQM is about.

$1----2-\cdots---3----4-----5$ 


\section{OPTIONAL QUESTIONS:}

The following questions are optional, but we would appreciate any additional information you would like to provide. We are interested in what you think.

a. What two things do you like the most about your organization?

b. What two things would you like to see improved in your organization?

c. Any additional comments you would like to make? 
58. Please indicate your present position classification by checking the most appropriate box:

Physician: Staff or house staff

Nurse: (RN, Clinical Specialist, Nurse Practitioner, Nurse

$$
\text { Educator, etc.) }
$$

Allicd Health Professional: (Pharmacist, Dietitian, PT, OT, Social

Worker, Medical Technologist, Optometrist, etc.)

Technical: (EEG Tech, Pharmacy Tech, PT/OT Assistant, LPN, OB/OR Tech, Respiratory / Pulmonary Tech, Radiology Tech, Nursing Assistant, Phlebotomist,etc.)

Office Support/Clerical: (Medical Records, Secretary, Admitting, Computer Operator, Communications, Finance \& Accounting, Personnel, Receptionist, Transcriptionist, etc.)

Service: (Food Service, Environmental Services, Supply / Warehouse Worker, Craftman, etc.)

Other

59. Rank or Pay Grade:

62. Age:
$\square$ I'VT - SPC
口 SGT - SSG
$\square$ SFC - CSM
口 WO - CWO
$\square 2 \mathrm{LT}-\mathrm{Cl}^{\prime} \mathrm{T}$
口 MAJ - LTC
$\square \mathrm{COL}$ and above
$\square$ WG 01.02
口WG $03-07$
$\square$ GS $1-5$
口GS $6-9$
$\square$ GS/M 10 \& above

63. Length of time at Tripler:

마이 0 -11 months

ㅁ $1-3 \mathrm{yrs}$

口 4 -9 yrs

ㅁ $10-20 \mathrm{yrs}$

$\square$ more than $20 \mathrm{yrs}$

60. Is your position designated as a supervisor, manager, or executive? Yes or No (circle one)

61. Gender: $M$ or F (circle one) 
63. Total federal and/or military service:
$\square$ - 0 -11 months
口 1 - 3 yrs
口 4-9 yrs
口 10 - 20yrs
$\square$ more than $20 \mathrm{yrs}$

When you have completed the survey, place it in the small, pre-
addressed envelope provided, and return addressed envelope provided, and return it through the distribution system.

Thank You for Sharing Your Opinions 
APPENDIX 2

ONE-WAY ANOVA RESULTS FOR OCCUPATION 
1. Jobs are clearly defined and logically structured

2. Is it unclear who has formal authority

3. Policies and organizational structure are clearly explained

4. Red tape is kept to a minimum

5. Excessive rules make it difficult for new ideas to receive consideration

6. Productivity suffers from lack of organization and planning

MEAN Std. Dev SIG 
7. Sometimes unsure who your boss is during projects

8. Abilities outweigh authority in selecting best people for project

9. Individual judgement is not relied upon

10. If you have the right approach, just go ahead

11. Supervisors set guidelines and allow subordinates to take responsibility

12. To get ahead at TAMC you must stick your neck out

\begin{tabular}{|c|c|c|c|c|}
\hline Total & 303 & 3.45 & 1.16 & \\
\hline physician & 42 & 2.29 & 0.94 & 0.006 \\
\hline nurse & 38 & 2.79 & 1.12 & \\
\hline allied health & 33 & 2.52 & 1.30 & \\
\hline technical & 62 & 2.63 & 1.22 & \\
\hline office/clerical support & 68 & 2.49 & 1.11 & \\
\hline service workers & 15 & 3.53 & 1.30 & \\
\hline Administartive & 45 & 2.18 & 1.39 & \\
\hline Total & 303 & 2.53 & 1.21 & \\
\hline physician & 42 & 3.07 & 0.97 & 0.304 \\
\hline nurse & 38 & 2.92 & 1.19 & \\
\hline allied health & 33 & 2.70 & 0.98 & \\
\hline technical & 62 & 3.18 & 1.03 & \\
\hline office/clerical support & 68 & 2.99 & 1.01 & \\
\hline service workers & 15 & 2.53 & 1.30 & \\
\hline Administartive & 45 & 3.02 & 1.29 & \\
\hline Total & 303 & 2.98 & 1.09 & \\
\hline physician & 42 & 2.81 & 0.94 & 0.914 \\
\hline nurse & 38 & 3.00 & 1.09 & \\
\hline allied health & 33 & 2.97 & 1.13 & \\
\hline technical & 62 & 3.06 & 1.10 & \\
\hline office/clerical support & 68 & 3.00 & 1.05 & \\
\hline service workers & 15 & 3.20 & 1.37 & \\
\hline Administartive & 45 & 2.93 & 1.25 & \\
\hline Total & 303 & 2.98 & 1.10 & \\
\hline physician & 42 & 2.52 & 0.77 & 0.49 \\
\hline nurse & 38 & 2.39 & 0.97 & \\
\hline allied health & 33 & 2.48 & 0.91 & \\
\hline technical & 62 & 2.55 & 0.95 & \\
\hline office/clerical support & 68 & 2.74 & 0.91 & \\
\hline service workers & 15 & 2.87 & 1.25 & \\
\hline Administartive & 45 & 2.56 & 0.92 & \\
\hline Total & 303 & 2.58 & 0.93 & \\
\hline physician & 42 & 3.17 & 1.06 & 0.765 \\
\hline nurse & 38 & 2.97 & 1.22 & \\
\hline allied health & 33 & 2.97 & 1.02 & \\
\hline technical & 62 & 3.16 & 1.04 & \\
\hline office/clerical support & 68 & 3.19 & 1.00 & \\
\hline service workers & 15 & 2.93 & 1.28 & \\
\hline Administartive & 45 & 3.29 & 1.10 & \\
\hline Total & 303 & 3.13 & 1.07 & \\
\hline physician & 42 & 2.95 & 0.99 & 0.367 \\
\hline nurse & 38 & 2.92 & 1.08 & \\
\hline allied health & 33 & 2.82 & 0.88 & \\
\hline technical & 62 & 2.94 & 1.10 & \\
\hline office/clerical support & 68 & 3.10 & 1.01 & \\
\hline service workers & $i 5$ & 2.60 & 1.40 & \\
\hline
\end{tabular}


13. People should solve problems by themselves

14. Lots of excuses when mistakes are made

15. Too many people are unwilling to take responsibility

16. The best rise to the top in our promotion system

18. Rewards and promotion is linked to excellence in job performance

\begin{tabular}{|c|c|c|c|c|}
\hline Administartive & 45 & 2.64 & 1.19 & \\
\hline Total & 303 & 2.90 & 1.07 & \\
\hline physician & 42 & 2.76 & 1.10 & 0.582 \\
\hline nurse & 38 & 2.87 & 1.12 & \\
\hline allied health & 33 & 2.39 & 0.66 & \\
\hline technical & 62 & 2.66 & 0.94 & \\
\hline office/clerical support & 68 & 2.75 & 0.89 & \\
\hline service workers & 15 & 2.53 & 1.41 & \\
\hline Administartive & 45 & 2.67 & 1.26 & \\
\hline Total & 303 & 2.69 & 1.03 & \\
\hline physician & 42 & 3.00 & 1.10 & .000 \\
\hline nurse & 38 & 3.37 & 1.02 & \\
\hline allied health & 33 & 2.76 & 1.00 & \\
\hline technical & 62 & 3.24 & 1.15 & \\
\hline office/clerical support & 68 & 3.44 & 1.07 & \\
\hline service workers & 15 & 4.20 & 0.94 & \\
\hline Administartive & 45 & 2.78 & 1.24 & \\
\hline Total & 303 & 3.19 & 1.14 & \\
\hline physician & 42 & 2.95 & 1.31 & 0.008 \\
\hline nurse & 38 & 3.37 & 1.17 & \\
\hline allied health & 33 & 3.03 & 1.21 & \\
\hline technical & 62 & 3.16 & 1.10 & \\
\hline office/clerical support & 68 & 3.47 & 1.20 & \\
\hline service workers & 15 & 3.93 & 1.22 & \\
\hline Administartive & 45 & 2.78 & 1.26 & \\
\hline Total & 303 & 3.19 & 1.23 & \\
\hline physician & 42 & 2.74 & 1.06 & 0.126 \\
\hline nurse & 38 & 2.45 & 1.16 & \\
\hline allied health & 33 & 2.06 & 0.97 & \\
\hline technical & 62 & 2.58 & 1.22 & \\
\hline office/clerical support & 68 & 2.22 & 0.94 & \\
\hline service workers & 15 & 2.53 & 1.55 & \\
\hline Administartive & 45 & 2.53 & 1.41 & \\
\hline Total & 303 & 2.44 & 1.17 & \\
\hline & & & i & \\
\hline physician & 42 & 3.26 & 1.08 & 0.027 \\
\hline nurse & 38 & 2.95 & 1.18 & \\
\hline allied health & 33 & 2.94 & 0.97 & \\
\hline technical & 62 & 2.76 & 1.13 & \\
\hline office/clerical support & 68 & 2.72 & 1.08 & \\
\hline service workers & 15 & 2.07 & 1.16 & \\
\hline Administartive $r$ & 45 & 2.96 & 1.40 & \\
\hline Total & 303 & 2.86 & 1.16 & \\
\hline physician & 42 & 2.95 & 0.94 & 0.35 \\
\hline nurse & 38 & 2.84 & 1.15 & \\
\hline allied health & 33 & 2.70 & 1.13 & \\
\hline technical & $\dot{6} 2$ & 2.47 & 1.08 & \\
\hline
\end{tabular}


19. Not enough reward and recognition for good work

20. Lots of criticism at TAMC

office/clerical support
service workers
Administartive
Total

$\begin{array}{ccc}68 & 2.57 & 1.18 \\ 15 & 2.47 & 1.41 \\ 45 & 2.80 & 1.34 \\ 303 & 2.68 & 1.16\end{array}$

physician

nurse

allied health

technical

$\begin{array}{lll}42 & 3.60 & 1.08\end{array}$

$\begin{array}{lll}38 & 3.82 & 1.23\end{array}$

$\begin{array}{lll}33 & 3.88 & 0.99\end{array}$

office/clerical support

$\begin{array}{lll}62 & 3.73 & 1.27\end{array}$

service workers

Administartive

Total

physician

nurse

allied health

technical

office/clerical support

service workers

Administartive

Total

$\begin{array}{lll}68 & 3.63 & 1.28\end{array}$

$15 \quad 4.00 \quad 1.25$

$\begin{array}{lll}45 & 3.24 & 1.33\end{array}$

$303 \quad 3.66 \quad 1.23$

$\begin{array}{lll}42 & 2.79 & 0.95\end{array}$

.000

$\begin{array}{lll}38 & 3.39 & 1.13\end{array}$

$\begin{array}{lll}33 & 2.88 & 1.08\end{array}$

$\begin{array}{lll}62 & 3.35 & 1.03\end{array}$

$\begin{array}{lll}68 & 3.37 & 1.11\end{array}$

$\begin{array}{lll}15 & 4.07 & 0.96\end{array}$

$\begin{array}{lll}45 & 2.82 & 1.28\end{array}$

$\begin{array}{lll}303 & 3.19 & 1.13\end{array}$

21. Make a mistake and you will be punished

physician
nurse
allied health
technical
office/clerical support
service workers
Administartive
Total

22. We get ahead by playing it slow, safe, sure

physician
nurse
allied health
technical
office/clerical support
service workers
Administartive
Total

23 We take calculated risks at the right time physician

nurse
allied health
technical
office/clerical support
service workers
Administartive
Total
physician
nurse
allied health

2.81

0.80

0.39

$\begin{array}{lll}38 & 2.79 & 1.04\end{array}$

$\begin{array}{lll}33 & 2.79 & 0.96\end{array}$

$\begin{array}{lll}62 & 2.79 & 1.03\end{array}$

$\begin{array}{lll}68 & 2.63 & 0.91\end{array}$

$\begin{array}{lll}15 & 3.33 & 0.98\end{array}$

$\begin{array}{lll}45 & 2.73 & 1.18\end{array}$

$\begin{array}{lll}303 & 2.78 & 0.99\end{array}$

$\begin{array}{lll}42 & 3.21 & 1.00\end{array}$

$38 \quad 3.16$

0.97

33

3.16

0.93

62

3.77

5.26

68

3.07

0.90

15

2.33

1.11

$45 \quad 2.64$

1.00

303

3.16

2.55

$42 \quad 3.05$

0.79

0.705

$38 \quad 3.24$

0.75

$\begin{array}{lll}33 & 3.15 & 0.83\end{array}$

$\begin{array}{lll}62 & 3.06 & 0.79\end{array}$

$\begin{array}{lll}68 & 3.03 & 0.71\end{array}$

$\begin{array}{lll}15 & 2.87 & 0.83\end{array}$

$\begin{array}{lll}45 & 2.98 & 0.92\end{array}$

$\begin{array}{lll}303 & 3.06 & 0.79\end{array}$

$\begin{array}{lll}42 & 2.83 & 0.82\end{array}$

$38 \quad 3.26 \quad 0.95$

$\begin{array}{lll}3.3 & 2.73 & 0.67\end{array}$

0.308

0.218

(1)

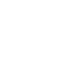<smiles>CCC</smiles><smiles>C1CCCC1</smiles>

24. Decision making is too cautious

allied health

0.048 
25. Management will take a chance on a good idea

technical
office/clerical support
service workers
Administartive
Total
physician
nurse
allied health
technical
office/clerical support
service workers
Administartive
Total

26. A friendly atmosphere prevails at TAMC

27. Relaxed, easy going climate at TAMC

$\begin{array}{ccc}62 & 3.00 & 0.89 \\ 68 & 3.03 & 0.98 \\ 15 & 3.20 & 1.08 \\ 45 & 2.69 & 0.92 \\ 303 & 2.95 & 0.91\end{array}$

$\begin{array}{lll}42 & 3.44 & 0.73\end{array}$

$\begin{array}{lll}38 & 3.32 & 1.07\end{array}$

$\begin{array}{lll}33 & 3.48 & 0.80\end{array}$

$\begin{array}{lll}62 & 3.47 & 0.80\end{array}$

$68 \cdot 3.41 \quad 0.90$

$\begin{array}{lll}15 & 2.87 & 1.19\end{array}$

$\begin{array}{lll}45 & 3.36 & 1.17\end{array}$

$\begin{array}{lll}303 & 3.39 & 0.93\end{array}$

$\begin{array}{llll}42 & 4.07 & 0.78 & 0.007\end{array}$

$\begin{array}{lll}38 & 3.58 & 0.95\end{array}$

$\begin{array}{lll}33 & 3.82 & 0.88\end{array}$

$\begin{array}{lll}62 & 3.60 & 1.03\end{array}$

$\begin{array}{lll}68 & 3.50 \quad 1.11\end{array}$

$\begin{array}{lll}15 & 2.87 & 1.36\end{array}$

$\begin{array}{lll}45 & 3.67 & 1.21\end{array}$

$\begin{array}{lll}303 & 3.64 & 1.06\end{array}$

$\begin{array}{lll}42 & 3.90 & 0.88\end{array}$

$\begin{array}{lll}38 & 3.21 & 1.12\end{array}$

$\begin{array}{lll}33 & 2.82 & 1.21\end{array}$

$\begin{array}{lll}62 & 3.27 & 1.09\end{array}$

$\begin{array}{lll}68 & 3.22 & 1.08\end{array}$

$\begin{array}{lll}15 & 2.53 & 1.19\end{array}$

$\begin{array}{lll}45 & 3.13 & 1.27\end{array}$

$\begin{array}{lll}303 & 3.23 & 1.15\end{array}$

$\begin{array}{lll}42 & 2.17 & 0.93\end{array}$

$\begin{array}{lll}38 & 2.37 & 0.85\end{array}$

$\begin{array}{lll}33 & 2.48 & 0.97\end{array}$

$\begin{array}{lll}62 & 2.69 & 1.17\end{array}$

$\begin{array}{lll}68 & 2.57 & 1.14\end{array}$

$\begin{array}{lll}15 & 2.80 & 1.08\end{array}$

$\begin{array}{lll}45 & 2.27 & 0.99\end{array}$

$\begin{array}{lll}303 & 2.47 & 1.05\end{array}$

$\begin{array}{lll}42 & 2.17 & 0.85\end{array}$

$\begin{array}{lll}38 & 2.61 & 0.97\end{array}$

$\begin{array}{lll}33 & 2.36 & 0.82\end{array}$

$\begin{array}{lll}62 & 2.73 & 0.98\end{array}$

$\begin{array}{lll}68 & 2.84 & 1.05\end{array}$

$\begin{array}{lll}15 & 2.87 & 1.19\end{array}$

$45 \quad 2.76 \quad 1.13$

$\begin{array}{lll}303 & 2.63 \quad 1.01\end{array}$

$\begin{array}{lll}42 & 3.56 & 0.93\end{array}$

$\begin{array}{lll}38 & 3.24 & 1.02\end{array}$

$\begin{array}{lll}33 & 3.21 \quad 1.08\end{array}$
0.433

.000

0.104

0.013

0.02
30. Warm relationship exist between
management and workers at TAMC

nurse

allied health 
31. Not much sympathy if you make a mistake

technical
office/clerical support
service workers
Administartive
Total
physician
nurse
allied health
technical
office/clerical support
service workers
Administartive
Total

32. Management talks with you about career aspirations

34. Management philosophy values how employee's feel

physician
nurse
allied health
technical
office/clerical support
service workers
Administartive
Total
physician
nurse
allied health
technical
office/clerical support
service workers
Administartive
Total

physician nurse

allied health

technical

office/clerical support

service workers

Administartive

Total

$\begin{array}{ccc}62 & 3.15 & 1.13 \\ 68 & 3.10 & 1.19 \\ 15 & 2.27 & 1.22 \\ 45 & 3.20 & 1.24 \\ 303 & 3.18 & 1.14\end{array}$

$\begin{array}{lll}42 & 2.74 & 0.83\end{array}$

$\begin{array}{lll}38 & 2.95 & 0.80\end{array}$

$\begin{array}{lll}33 & 2.97 & 0.92\end{array}$

$\begin{array}{lll}62 & 3.05 & 1.03\end{array}$

$\begin{array}{lll}68 & 2.94 & 0.98\end{array}$

$\begin{array}{lll}15 & 3.73 & 0.88\end{array}$

$\begin{array}{lll}45 & 2.91 & 1.16\end{array}$

$\begin{array}{lll}303 & 2.97 & 0.98\end{array}$

38

33

62

68

15

45

303

42

38

33

62

68

15

45

303

3.31

3.18

1.02

1.14

2.79

1.14

2.90

1.13

2.68

2.00

1.14

3.11

1.07

1.34

2.92

1.18

2.24

0.73

3.16

1.31

$3.00 \quad 1.09$

$3.02 \quad 1.00$

$3.13 \quad 1.09$

$3.27 \quad 1.16$

$2.73 \quad 1.23$

2.92 .

1.12

$\begin{array}{lll}42 & 3.31 & 0.72\end{array}$

$\begin{array}{lll}38 & 2.95 & 0.93\end{array}$

$\begin{array}{lll}33 & 2.88 & 1.22\end{array}$

$\begin{array}{lll}62 & 3.00 & 1.02\end{array}$

$\begin{array}{lll}68 & 2.84 & 1.00\end{array}$

$\begin{array}{lll}15 & 2.47 & 1.13\end{array}$

$\begin{array}{lll}45 & 2.96 & 1.17\end{array}$

$303 \quad 2.95 \quad 1.03$

35. Employee's can count on management support in difficult assignments

physician
nurse
allied health
technical
office/clerical support
service workers
Administartive
Total

$\begin{array}{ccc}42 & 3.88 & 0.71 \\ 38 & 3.34 & 1.05 \\ 33 & 3.76 & 1.03 \\ 62 & 3.74 & 1.01 \\ 68 & 3.38 & 1.07 \\ 15 & 3.00 & 1.20 \\ 45 & 3.67 & 1.11 \\ 303 & 3.58 & 1.04\end{array}$

0.058

0.002

0.001

0.144

0.015 
36. High performance standards are set at TAMC

\begin{tabular}{|c|c|c|c|c|}
\hline physician & 42 & 3.94 & 0.77 & 0.38 \\
\hline nurse & 38 & 3.79 & 0.87 & \\
\hline allied health & 33 & 4.00 & 0.71 & \\
\hline technical & 62 & 3.77 & 1.00 & \\
\hline office/clerical support & 68 & 3.62 & 1.05 & \\
\hline service workers & 15 & 3.53 & 0.92 & \\
\hline Administartive & 45 & 3.87 & 1.04 & \\
\hline Total & 303 & 3.79 & 0.94 & \\
\hline physician & 42 & 3.55 & 0.97 & 0.544 \\
\hline nurse & 38 & 3.42 & 1.13 & \\
\hline allied health & 33 & 3.61 & 0.83 & \\
\hline technical & 62 & 3.44 & 0.99 & \\
\hline office/clerical support & 68 & 3.56 & 0.89 & \\
\hline service workers & 15 & 3.00 & 1.13 & \\
\hline Administartive & 45 & 3.51 & 1.08 & \\
\hline Total & 303 & 3.49 & 0.99 & \\
\hline physician & 42 & 3.38 & 0.94 & 0.404 \\
\hline nurse & 38 & 3.66 & 0.97 & \\
\hline allied health & 33 & 3.64 & 0.90 & \\
\hline technical & 62 & 3.45 & 1.10 & \\
\hline office/clerical support & 68 & 3.31 & 1.00 & \\
\hline service workers & 15 & 3.07 & 1.16 & \\
\hline Administartive & 45 & 3.44 & 1.12 & \\
\hline Total & 303 & 3.44 & 1.02 & \\
\hline
\end{tabular}

39. Management believes that if people are happy, productivity will take care of itself

physician
nurse
allied health
technical
office/clerical support
service workers
Administartive
Total

$\begin{array}{lll}42 & 286 & 0.91\end{array}$

0.299

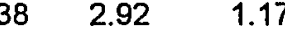

$\begin{array}{lll}33 & 2.76 & 1.12\end{array}$

$\begin{array}{lll}62 & 3.15 & 1.05\end{array}$

$\begin{array}{lll}68 & 2.78 & 1.09\end{array}$

$\begin{array}{lll}15 & 2.60 \quad 1.06\end{array}$

$\begin{array}{lll}45 & 3.11 & 1.23\end{array}$

$\begin{array}{lll}303 & 2.92 \quad 1.10\end{array}$

40. To get ahead it is more important to get along than to be a high producer

physician

$\begin{array}{lll}42 & 3.02 & 0.90\end{array}$

0.076

nurse

$38 \quad 3.29$

1.09

allied health

$33 \quad 3.24$

0.94

technical

$62 \quad 3.32$

1.10

office/clerical support

$68 \quad 3.15$

1.08

service workers

$15 \quad 3.60$

0.91

Administartive .

$45 \quad 2.78$

1.15

Total

$303 \quad 3.16$

1.06

41. At TAMC people don't take pride in their performance

physician
nurse
allied health
technical
office/clerical support

$\begin{array}{lll}42 & 2.23 & 0.81 \\ 38 & 2.68 & 1.14 \\ 33 & 2.45 & 1.00 \\ 62 & 2.79 & 1.15 \\ 68 & 2.96 & 1.15\end{array}$

.000 
42. The best way to make a good impression is to avoid arguments and disagreements

service workers
Administartive
Total

43. Management feels conflict between competing departments can be healthy

44. Employees are encouraged to speak their minds even if disagreeing

45. At meetings the goal is to make decisions smoothly and quickly

46. People are proud to belong to TAMC

47. I am a member of a well functioning team

physician

nurse

allied health

technical

service workers

Administartive

Total

physician

nurse

allied health

technical

service workers

Administartive

Total

physician

nurse

allied health

technical

service workers

Administartive

Total

physician

nurse

allied health

technical

Administartive

Total

physician

$\begin{array}{ccc}15 & 3.27 & 1.33 \\ 45 & 2.07 & 1.12 \\ 303 & 2.62 & 1.14\end{array}$

physician
nurse
allied health
technical
office/clerical support
service workers
Administartive
Total

$\begin{array}{cccc}42 & 3.21 & 1.00 & 0.098 \\ 38 & 3.34 & 1.19 & \\ 33 & 3.55 & 1.03 & \\ 62 & 3.44 & 1.10 & \\ 68 & 3.44 & 1.03 & \\ 15 & 3.93 & 0.96 & \\ 45 & 3.02 & 1.23 & \\ 303 & 3.37 & 1.10 & \end{array}$

office/clerical support

$\begin{array}{lll}42 & 2.71 & 0.81 \\ 38 & 2.79 & 0.87\end{array}$

0.665

$\begin{array}{lll}33 & 2.94 & 0.83\end{array}$

$\begin{array}{lll}62 & 2.66 & 0.81\end{array}$

$\begin{array}{lll}68 & 2.78 & 0.81\end{array}$

$\begin{array}{lll}15 & 2.60 & 0.91\end{array}$

$\begin{array}{lll}45 & 2.62 & 0.86\end{array}$

$\begin{array}{lll}303 & 2.73 & 0.83\end{array}$

office/clerical support

$42 \quad 3.00$

1.01

1.09

$38 \quad 2.79$

$33 \quad 2.79$

0.96

$62 \quad 2.82$

1.27

$\begin{array}{ll}68 & 2.88\end{array}$

1.14

$15 \quad 2.47$

$45 \quad 3.09$

$303 \quad 2.87$

1.19

1.12

1.13

0.74

1.05

$42 \quad 3.29$

$38 \quad 3.03$

$33 \quad 3.00$

0.87

$62 \quad 3.23$

0.89

office/clerical support

$68 \quad 3.34$

1.02

$15 \quad 3.20$

0.94

$45 \quad 3.11$

1.13

$303 \quad 3.19$

0.96

3.79

0.72

1.00

3.39

0.88

3.73

1.09

office/clerical support

3.35

1.04

service workers.

3.40

0.68

3.20

1.12

$45 \quad 3.49$

0.99

nurse

$42 \quad 3.60$

0.96

0.149 
48. People are not loyal to TAMC

49. People at TAMC just look out for themselves

50. Leadership is actively involved in promoting TQM

$$
\begin{aligned}
& \text { tech } \\
& \text { offic } \\
& \text { Adm } \\
& \text { Tota } \\
& \text { phy } \\
& \text { nur } \\
& \text { allie } \\
& \text { tech } \\
& \text { office } \\
& \text { ser } \\
& \text { Adm }
\end{aligned}
$$

52. My supervisor is strongly committed to TQM

53. TQM is important to me

physician
nurse
allied health
technical
office/clerical support
service workers
Administartive
Total
physician
nurse
allied health
technical
office/clerical support
service workers
Administartive
Total
physician
nurse
allied health

$\begin{array}{cccc}62 & 3.42 & 1.11 & \\ 68 & 3.49 & 1.18 & \\ 15 & 2.67 & 0.98 & \\ 45 & 3.29 & 1.24 & \\ 303 & 3.42 & 1.11 & \\ 42 & 2.37 & 0.79 & 0.029 \\ 38 & 2.76 & 1.17 & \\ 33 & 2.42 & 1.00 & \\ 62 & 2.92 & 1.06 & \\ 68 & 2.79 & 1.07 & \\ 15 & 2.87 & 1.13 & \\ 45 & 2.36 & 1.15 & \\ 303 & 2.66 & 1.07\end{array}$

$\begin{array}{lll}303 & 2.66 \quad 1.07\end{array}$

$\begin{array}{lll}42 & 2.61 & 0.82\end{array}$

$\begin{array}{lll}38 & 3.11 & 1.18\end{array}$

$\begin{array}{lll}33 & 3.09 & 1.04\end{array}$

$\begin{array}{lll}62 & 3.47 & 1.08\end{array}$

$\begin{array}{lll}68 & 3.49 & 1.19\end{array}$

$\begin{array}{lll}15 & 3.73 & 1.22\end{array}$

$\begin{array}{lll}45 & 2.98 & 1.37\end{array}$

$\begin{array}{lll}303 & 3.21 & 1.17\end{array}$

$\begin{array}{llll}42 & 3.86 & 0.78 & 0.194\end{array}$

$\begin{array}{lll}38 & 3.50 & 0.92\end{array}$

$\begin{array}{lll}33 & 3.48 & 0.80\end{array}$

$\begin{array}{lll}62 & 3.56 & 0.84\end{array}$

$\begin{array}{lll}68 & 3.38 & 0.91\end{array}$

$\begin{array}{lll}15 & 3.27 & 0.88\end{array}$

$\begin{array}{lll}45 & 3.51 & 1.14\end{array}$

$\begin{array}{lll}303 & 3.52 & 0.91\end{array}$

$\begin{array}{lll}42 & 3.86 & 0.87\end{array}$

$\begin{array}{lll}38 & 3.42 & 0.95\end{array}$

$\begin{array}{lll}33 & 3.36 & 0.99\end{array}$

$\begin{array}{lll}62 & 3.47 & 1.05\end{array}$

$\begin{array}{lll}68 & 3.32 & 0.95\end{array}$

$\begin{array}{lll}15 & 3.07 & 1.03\end{array}$

$\begin{array}{lll}45 & 3.22 & 1.20\end{array}$

$\begin{array}{lll}303 & 3.42 \quad 1.02\end{array}$

$\begin{array}{llll}42 & 3.76 & 0.82 & 0.383\end{array}$

$\begin{array}{lll}38 & 3.61 & 1.03\end{array}$

$\begin{array}{lll}33 & 3.55 & 1.00\end{array}$

$\begin{array}{lll}62 & 3.47 & 1.11\end{array}$

$\begin{array}{lll}68 & 3.53 & 1.09\end{array}$

$\begin{array}{lll}15 & 3.00 & 1.13\end{array}$

$\begin{array}{lll}45 & 3.49 & 1.10\end{array}$

$\begin{array}{lll}303 & 3.53 & 1.05\end{array}$

$\begin{array}{lll}42 & 3.56 & 1.12\end{array}$

$\begin{array}{lll}38 & 4.03 & 0.91\end{array}$

$\begin{array}{lll}33 & 3.82 & 0.88\end{array}$

0.001 
54. I understand my role in contributing to TQM goals

55. I understand how TQM is being implemented at TAMC

56. I don't know much about TQM

technical
office/clerical support
service workers
Administartive
Total
physician
nurse
allied health
technical
office/clerical support
service workers
Administartive
Total
physician
nurse
allied health
technical
office/clerical support
service workers
Administartive
Total
physician
nurse
allied health
technical
office/clerical support
service workers
Administartive
Total

\section{2}

$68 \quad 4.01$

$15 \quad 4.00$

$45 \quad 3.98$

$303 \quad 3.92$

$42 \quad 3.64$

38

33

62

68

15

45

303

42

38

33

62

68

15

45

303

42

38

33

62

68

$2.41 \quad 1.24$

$\begin{array}{lll}15 & 2.40 \quad 1.18\end{array}$

$\begin{array}{lll}45 & 1.98 & 1.23\end{array}$

$\begin{array}{lll}303 & 2.22 \quad 1.15\end{array}$
0.202

0.386

$3.37 \quad 0.88$

$3.12 \quad 0.78$

$3.56 \quad 0.97$

$3.35 \quad 1.09$

$3.20 \quad 1.01$

$3.49 \quad 1.12$

$3.36 \quad 1.02$

$2.10 \quad 1.12$

$\begin{array}{ll}1.97 & 0.88\end{array}$

$2.45 \quad 1.20$

1.12

1. Questions listed are in abbreviated form.

2. Question means are not recoded and reflect actual values

3. Significance listed is from One-way ANOVA test 



\begin{tabular}{|c|c|c|c|c|c|}
\hline & Status & $\mathbf{N}$ & MEA & Std. Dev & SIG \\
\hline \multirow[t]{4}{*}{ 1. Jobs are clearly defined and logically structured } & Enlisted & 73 & 3.32 & 1.07 & 0.009 \\
\hline & Officer & 75 & 3.75 & 0.86 & \\
\hline & Civilian & 155 & 3.35 & 1.02 & \\
\hline & Total & 303 & 3.45 & 1.01 & \\
\hline \multirow[t]{4}{*}{ 2. Is it unclear who has formal authority } & Enlisted & 73 & 2.94 & 1.44 & 0.011 \\
\hline & Officer & 75 & 2.47 & 1.20 & \\
\hline & Civilian & 155 & 3.01 & 1.28 & \\
\hline & Total & 303 & 2.86 & 1.32 & \\
\hline \multirow[t]{4}{*}{ 3. Policies and organizational structure clearly explained } & Enlisted & 73 & 3.26 & 1.19 & 0.048 \\
\hline & Officer & 75 & 3.68 & 1.02 & \\
\hline & Civilian & 155 & 3.57 & 1.04 & \\
\hline & Total & 303 & 3.53 & 1.08 & \\
\hline \multirow[t]{4}{*}{ 4. Red tape is kept to a minimum } & Enlisted & 73 & 2.71 & 1.09 & 0.124 \\
\hline & Officer & 75 & 2.54 & 1.12 & \\
\hline & Civilian & 155 & 2.85 & 1.03 & \\
\hline & Total & 303 & 2.74 & 1.07 & \\
\hline \multirow{4}{*}{$\begin{array}{l}\text { 5. Excessive rules make it difficult for new ideas to } \\
\text { receive consideration }\end{array}$} & Enlisted & 73 & 3.25 & 1.21 & 0.048 \\
\hline & Officer & 75 & 2.87 & 1.20 & \\
\hline & Civilian & 155 & 3.25 & 1.10 & \\
\hline & Total & 303 & 3.15 & 1.16 & \\
\hline \multirow{4}{*}{$\begin{array}{l}\text { 6. Productivity suffers from lack of organization and } \\
\text { planning }\end{array}$} & Enlisted & 73 & 3.56 & 1.06 & 0.656 \\
\hline & Officer & 75 & 3.39 & 1.20 & \\
\hline & Civilian & 155 & 3.43 & 1.20 & \\
\hline & Total & 303 & 3.45 & 1.17 & \\
\hline \multirow[t]{4}{*}{ 7. Unsure who your boss is sometimes during projects } & Enlisted & 73 & 2.68 & 1.34 & 0.040 \\
\hline & Officer & 75 & 2.23 & 0.98 & \\
\hline & Civilian & 155 & 2.61 & 1.24 & \\
\hline & Total & 303 & 2.53 & 1.21 & \\
\hline \multirow{4}{*}{$\begin{array}{l}\text { 8. Abilities outweigh authority in selecting best } \\
\text { people for a project }\end{array}$} & Enlisted & 73 & 2.93 & 1.24 & 0.869 \\
\hline & Officer & 75 & 3.03 & 1.03 & \\
\hline & Civilian & 155 & 2.98 & 1.07 & \\
\hline & Total & 303 & 2.98 & 1.10 & \\
\hline \multirow[t]{4}{*}{ 9. Individual judgement is not relied upon } & Enlisted & 73 & 3.10 & 1.12 & 0.185 \\
\hline & Officer & 75 & 2.79 & 0.98 & \\
\hline & Civilian & 155 & 3.03 & 1.15 & \\
\hline & Total & 303 & 2.98 & 1.10 & \\
\hline \multirow[t]{4}{*}{ 10. If you have the right approach, just go ahead } & Enlisted & 73 & 2.44 & 1.01 & 0.089 \\
\hline & Officer & 75 & 2.47 & 0.83 & \\
\hline & Civilian & 155 & 2.69 & 0.93 & \\
\hline & Total & 303 & 2.58 & 0.93 & \\
\hline \multirow{4}{*}{$\begin{array}{l}\text { 11. Supervisors set guidelines and allow subordinates } \\
\text { to take responsibility }\end{array}$} & Enlisted & 73 & 3.00 & 1.15 & 0.113 \\
\hline & Officer & 75 & 3.00 & 1.14 & \\
\hline & Civilian & 155 & 3.26 & 0.99 & \\
\hline & Total & 303 & 3.13 & 1.07 & \\
\hline \multirow[t]{4}{*}{ 12. To get ahead at TAMC you must stick your neck out } & Enlisted & 73 & 2.88 & 1.22 & 0.776 \\
\hline & Officer & 75 & 2.84 & 0.93 & \\
\hline & Civilian & 155 & 2.94 & 1.07 & \\
\hline & Total & 303 & 2.90 & 1.07 & \\
\hline
\end{tabular}


13. People should solve problems by themselves

14. Lots of excuses when mistakes are made

16. The best rise to the top in our promotion system

17. Rewards outweigh threats and criticisms

18. Rewards and promotion is linked to excellence in job performance

19. Not enough reward and recognition for good work

20. Lots of criticism at TAMC

21. Make a mistake and you will be punished

22. We get ahead by playing it slow, safe, sure

23 We take calculated risks at the right time

24. Decision making is too cautious

\begin{tabular}{|c|c|c|c|c|}
\hline Enlisted & 73 & 2.49 & 1.10 & 0.169 \\
\hline Officer & 75 & 2.76 & 1.06 & \\
\hline Civilian & 155 & 2.74 & 0.97 & \\
\hline Total & 303 & 2.69 & 1.03 & \\
\hline Enlisted & 73 & 3.46 & 1.23 & 0.008 \\
\hline Officer & 75 & 2.88 & 1.04 & \\
\hline Civilian & 155 & 3.22 & 1.12 & \\
\hline Total & 303 & 3.19 & 1.15 & \\
\hline Enlisted & 73 & 3.35 & 1.28 & 0.047 \\
\hline Officer & 75 & 2.89 & 1.18 & \\
\hline Civilian & 155 & 3.26 & 1.21 & \\
\hline Total & 303 & 3.19 & 1.23 & \\
\hline Enlisted & 73 & 2.50 & 1.40 & 0.250 \\
\hline Officer & 75 & 2.59 & 1.05 & \\
\hline Civilian & 155 & 2.33 & 1.09 & \\
\hline Total & 303 & 2.43 & 1.16 & \\
\hline Enlisted & 73 & 2.61 & 1.34 & 0.008 \\
\hline Officer & 75 & 3.19 & 1.07 & \\
\hline Civilian & 155 & 2.81 & 1.09 & \\
\hline Total & 303 & 2.85 & 1.16 & \\
\hline Enlisted & 73 & 2.54 & 1.27 & 0.218 \\
\hline Officer & 75 & 2.87 & 0.99 & \\
\hline Civilian & 155 & 2.65 & 1.18 & \\
\hline Total & 303 & 2.68 & 1.16 & \\
\hline Enlisted & 73 & 3.69 & 1.37 & 0.951 \\
\hline Officer & 75 & 3.65 & 1.14 & \\
\hline Civilian & 155 & 3.64 & 1.21 & \\
\hline Total & 303 & 3.66 & 1.23 & \\
\hline Enlisted & 73 & 3.47 & 1.19 & 0.010 \\
\hline Officer & 75 & 2.91 & 1.05 & \\
\hline Civilian & 155 & 3.19 & 1.12 & \\
\hline Total & 303 & 3.19 & 1.13 & \\
\hline Enlisted & 73 & 3.14 & 1.10 & 0.002 \\
\hline Officer & 75 & 2.68 & 0.84 & \\
\hline Civilian & 155 & 2.65 & 0.97 & \\
\hline Total & 303 & 2.77 & 0.99 & \\
\hline Enlisted & 73 & 3.71 & 4.91 & 0.112 \\
\hline Officer & 75 & 2.92 & 1.01 & \\
\hline Civilian & 155 & 3.03 & 0.96 & \\
\hline Total & 303 & 3.17 & 2.55 & \\
\hline Enlisted & 73 & 2.97 & 0.90 & 0.053 \\
\hline Officer & 75 & 3.25 & 0.79 & \\
\hline Civilian & 155 & 3.01 & 0.73 & \\
\hline Total & 303 & 3.06 & 0.79 & \\
\hline Enlisted & 73 & 3.00 & 0.99 & 0.114 \\
\hline Officer & 75 & 2.76 & 0.80 & \\
\hline Civilian & 155 & 3.02 & 0.92 & \\
\hline Total & 303 & 2.95 & 0.92 & \\
\hline
\end{tabular}


25. Management will take a chance on a good idea

26. A friendly atmosphere prevails at TAMC

27. Relaxed, easy going climate at TAMC

28. It is hard to get to know people at TAMC

29. At TAMC people are cool and aloof

30. Warm relationship exist between management and workers at TAMC

31. Not much sympathy if you make a mistake

32. Management talks with you about career aspirations

33. People don't trust each other at TAMC

34. Management philosophy values how employee's feel

35. Employee's can count on management support in difficult assignments

36. High performance standards are set at TAMC

\begin{tabular}{|c|c|c|c|c|}
\hline Enlisted & 73 & 3.28 & 1.00 & 0.356 \\
\hline Officer & 75 & 3.50 & 0.83 & \\
\hline Civilian & 155 & 3.39 & 0.96 & \\
\hline Total & 303 & 3.39 & 0.94 & \\
\hline Enlisted & 73 & 3.36 & 1.32 & 0.001 \\
\hline Officer & 75 & 4.01 & 0.80 & \\
\hline Civilian & 155 & 3.58 & 0.99 & \\
\hline Total & 303 & 3.64 & 1.06 & \\
\hline Enlisted & 73 & 3.03 & 1.24 & 0.006 \\
\hline Officer & 75 & 3.59 & 1.04 & \\
\hline Civilian & 155 & 3.15 & 1.12 & \\
\hline Total & 303 & 3.23 & 1.15 & \\
\hline Enlisted & 73 & 2.67 & 1.22 & 0.028 \\
\hline Officer & 75 & 2.21 & 0.89 & \\
\hline Civilian & 155 & 2.50 & 1.02 & \\
\hline Total & 303 & 2.47 & 1.05 & \\
\hline Enlisted & 73 & 2.86 & 1.05 & 0.001 \\
\hline Officer & 75 & 2.28 & 0.91 & \\
\hline Civilian & 155 & 2.69 & 1.01 & \\
\hline Total & 303 & 2.63 & 1.02 & \\
\hline Enlisted & 73 & 2.90 & 1.22 & 0.004 \\
\hline Officer & 75 & 3.51 & 0.94 & \\
\hline Civilian & 155 & 3.14 & 1.15 & \\
\hline Total & 303 & 3.17 & 1.14 & \\
\hline Enlisted & 73 & 3.13 & 1.19 & 0.106 \\
\hline Officer & 75 & 2.79 & 0.84 & \\
\hline Civilian & 155 & 2.99 & 0.93 & \\
\hline Total & 303 & 2.97 & 0.98 & \\
\hline Enlisted & 73 & 2.92 & 1.22 & 0.000 \\
\hline Officer & 75 & 3.41 & 1.01 & \\
\hline Civilian & 155 & 2.67 & 1.16 & \\
\hline Total & 303 & 2.91 & 1.18 & \\
\hline Enlisted & 73 & 3.19 & 1.22 & 0.000 \\
\hline Officer & 75 & 2.47 . & 1.02 & \\
\hline Civilian & 155 & 3.01 & 1.06 & \\
\hline Total & 303 & 2.92 & 1.12 & \\
\hline Enlisted & 73 & 2.85 & 1.11 & 0.231 \\
\hline Officer & 75 & 3.12 & 0.87 & \\
\hline Civilian & 155 & 2.92 & 1.06 & \\
\hline Total & 303 & 2.95 & 1.03 & \\
\hline Enlisted & 73 & 3.40 & 1.16 & 0.029 \\
\hline Officer & 75 & 3.84 & 0.82 & \\
\hline Civilian & 155 & 3.54 & 1.05 & \\
\hline Total & 303 & 3.58 & 1.04 & \\
\hline Enlisted & 73 & 3.72 & 1.06 & 0.172 \\
\hline Officer & 75 & 3.97 & 0.77 & \\
\hline Civilian & 155 & 3.74 & 0.95 & \\
\hline Total & 303 & 3.79 & 0.94 & \\
\hline
\end{tabular}


37. Management believes that no job is so well done that it couldn't be done better

\begin{tabular}{|c|c|c|c|c|}
\hline Enlisted & 73 & 3.47 & 1.05 & 0.757 \\
\hline Officer & 75 & 3.56 & 0.96 & \\
\hline Civilian & 155 & 3.46 & 0.98 & \\
\hline Total & 303 & 3.49 & 0.99 & \\
\hline Enlisted & 73 & 3.33 & 1.16 & 0.078 \\
\hline Officer & 75 & 3.67 & 0.92 & \\
\hline Civilian & 155 & 3.37 & 0.99 & \\
\hline Total & 303 & 3.44 & 1.03 & \\
\hline Enlisted & 73 & 2.86 & 1.21 & 0.791 \\
\hline Officer & 75 & 2.89 & 0.98 & \\
\hline Civilian & 155 & 2.96 & 1.10 & \\
\hline Total & 303 & 2.92 & 1.10 & \\
\hline Enlisted & 73 & 3.19 & 1.22 & 0.248 \\
\hline Officer & 75 & 2.99 & 1.06 & \\
\hline Civilian & 155 & 3.23 & 0.98 & \\
\hline Total & 303 & 3.16 & 1.06 & \\
\hline Enlisted & 73 & 2.79 & 1.29 & 0.002 \\
\hline Officer & 75 & 2.21 & 0.90 & \\
\hline Civilian & 155 & 2.72 & 1.13 & \\
\hline Total & 303 & 2.61 & 1.14 & \\
\hline Enlisted & 73 & 3.46 & 1.20 & 0.166 \\
\hline Officer & 75 & 3.16 & 1.09 & \\
\hline Civilian & 155 & 3.43 & 1.05 & \\
\hline Total & 303 & 3.37 & 1.10 & \\
\hline Enlisted & 73 & 2.72 & 0.88 & 0.908 \\
\hline Officer & 75 & 2.71 & 0.80 & \\
\hline Civilian & 155 & 2.75 & 0.82 & \\
\hline Total & 303 & 2.74 & 0.83 & \\
\hline Enlisted & 73 & 2.65 & 1.26 & 0.167 \\
\hline Officer & 75 & 2.96 & 1.02 & \\
\hline Civilian & 155 & 2.93 & 1.11 & \\
\hline Total & 303 & 2.87 & 1.13 & \\
\hline Enlisted & 73 & 3.04 & 1.12 & 0.294 \\
\hline Officer & 75 & 3.23 & 0.89 & \\
\hline Civilian & 155 & 3.25 & 0.91 & \\
\hline Total & 303 & 3.20 & 0.96 & \\
\hline Enlisted & 73 & 3.26 & 1.16 & 0.065 \\
\hline Officer & 75 & 3.64 & 0.88 & \\
\hline Civilian & 155 & 3.51 & 0.95 & \\
\hline Total & 303 & 3.48 & 0.99 & \\
\hline Enlisted & 73 & 3.14 & 1.23 & 0.026 \\
\hline Officer & 75 & 3.63 & 1.00 & \\
\hline Civilian & 155 & 3.45 & 1.09 & \\
\hline Total & 303 & 3.42 & 1.11 & \\
\hline Enlisted & 73 & 2.96 & 1.17 & 0.001 \\
\hline Officer & 75 & 2.33 & 0.93 & \\
\hline Civilian & 155 & 2.66 & 1.05 & \\
\hline Total & 303 & 2.65 & 1.07 & \\
\hline
\end{tabular}

44. Employees are encouraged to speak their minds even if disagreeing

45. At meetings the goal is to make decisions smoothly and quickly

46. People are proud to belong to TAMC

47. I am a member of a well functioning team

48. People are not loyal to TAMC

39. Management believes that if ped
productivity will take care of itself

To get ahead it is more important to get along than to be a high producer

41. At TAMC people don't take pride in their performance

43. Management feels conflict between competing departments can be healthy

42. The best way to make a good impression is to avoid arguments and disagreements

\author{
47. I am a member of a well functioning team
}


49. People at TAMC just look out for themselves

$\begin{array}{lcccc}\text { Enlisted } & 73 & 3.47 & 1.28 & \mathbf{0 . 0 0 0} \\ \text { Officer } & 75 & 2.75 & 1.04 & \\ \text { Civilian } & 155 & 3.30 & 1.13 & \\ \text { Total } & 303 & 3.20 & 1.18 & \\ \text { Enlisted } & 73 & 3.33 & 0.99 & \mathbf{0 . 0 0 3} \\ \text { Officer } & 75 & 3.81 & 0.90 & \\ \text { Civilian } & 155 & 3.47 & 0.86 & \\ \text { Total } & 303 & 3.52 & 0.91 & \\ \text { Enlisted } & 73 & 3.21 & 1.14 & 0.029 \\ \text { Officer } & 75 & 3.65 & 1.02 & \\ \text { Civilian } & 155 & 3.39 & 0.95 & \\ \text { Total } & 303 & 3.41 & 1.02 & \\ \text { Enlisted } & 73 & 3.40 & 1.16 & 0.076 \\ \text { Officer } & 75 & 3.76 & 0.94 & \\ \text { Civilian } & 155 & 3.47 & 1.03 & \\ \text { Total } & 303 & 3.53 & 1.05 & \\ \text { Enlisted } & 73 & 3.97 & 1.02 & 0.703 \\ \text { Officer } & 75 & 3.85 & 1.06 & \\ \text { Civilian } & 155 & 3.94 & 0.86 & \\ \text { Total } & 303 & 3.92 & 0.95 & \\ \text { Enlisted } & 73 & 3.83 & 0.96 & 0.818 \\ \text { Officer } & 75 & 3.76 & 1.04 & \\ \text { Civilian } & 155 & 3.75 & 0.91 & \\ \text { Total } & 303 & 3.77 & 0.95 & \end{array}$

51. Senior management action shows strong commitment to TQM

52. My supervisor is strongly committed to TQM

53. TQM is important to me

54. I understand my role in contributing to TQM goals

$\begin{array}{lccc}\text { Enlisted } & 73 & 3.42 & 1.10 \\ \text { Officer } & 75 & 3.35 & 1.13 \\ \text { Civilian } & 155 & 3.34 & 0.94 \\ \text { Total } & 303 & 3.36 & 1.02 \\ \text { Enlisted } & 73 & 2.26 & 1.33 \\ \text { Officer } & 75 & 1.89 & 0.99 \\ \text { Civilian } & 155 & 2.34 & 1.10 \\ \text { Total } & 303 & 2.21 & 1.14\end{array}$

55. I understand how TQM is being implemented at TAMC Enlisted $\begin{array}{lllll}73 & 3.42 & 1.10 & 0.874\end{array}$

56. I don't know much about TQM

1. Questions listed are in abbreviated form.

2. Question means are not recoded and reflect actual values

3. Significance listed is from One-way ANOVA test 
APPENDIX 4

MEAN CONSTRUCT AND SELECT QUESTION COMPARISON 


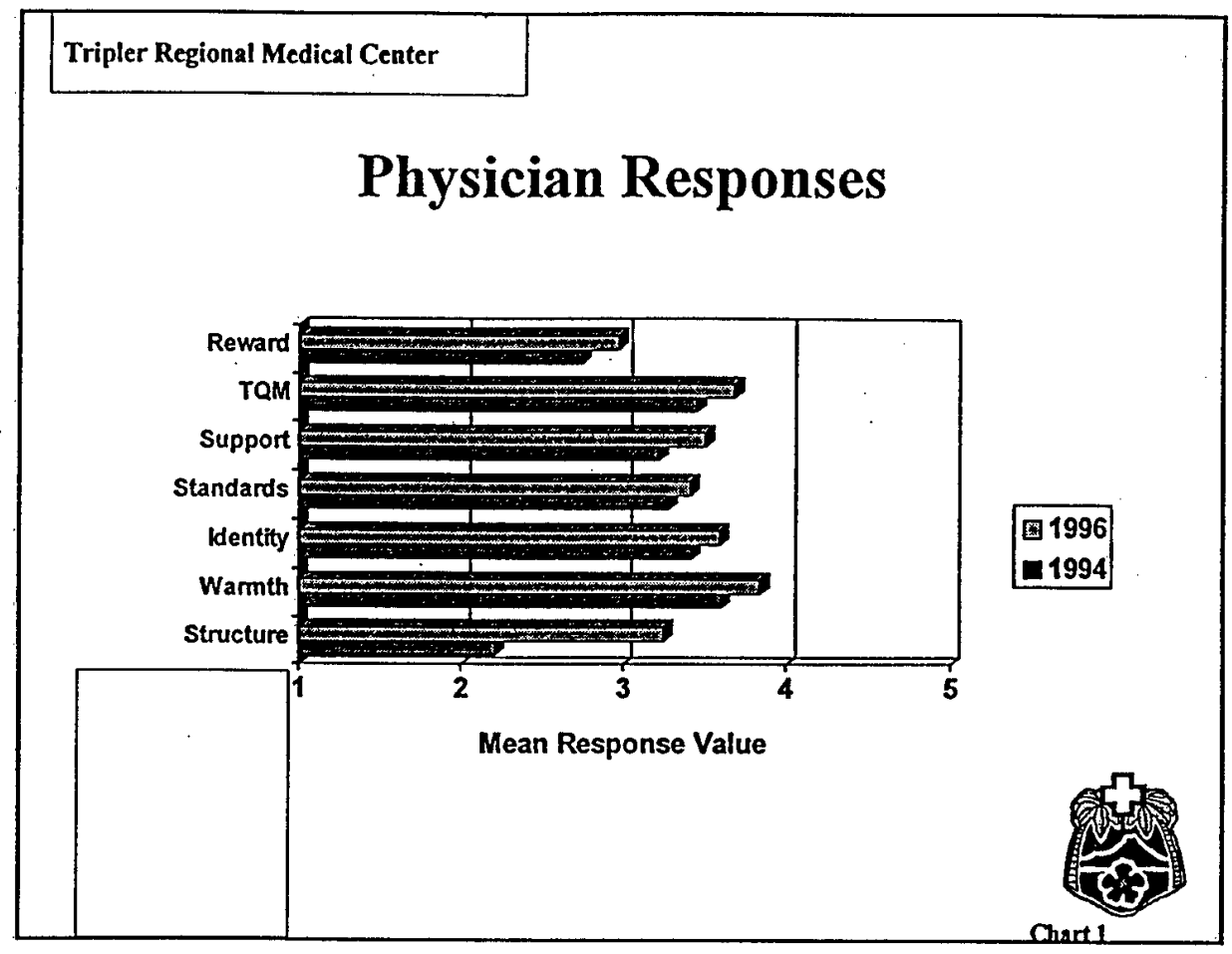

Tripler Regional Medical Center

\section{Service Workers Responses}

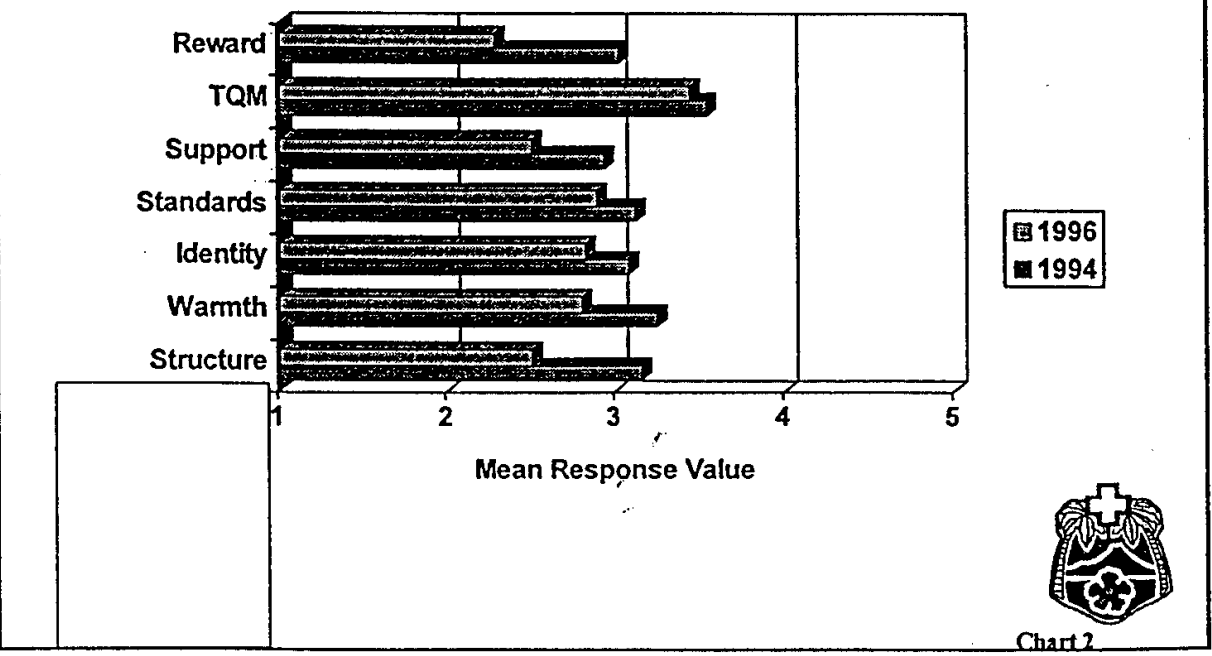


Tripler Regional Medical Center

Supervisor-Non Supervisor Responses (1996)

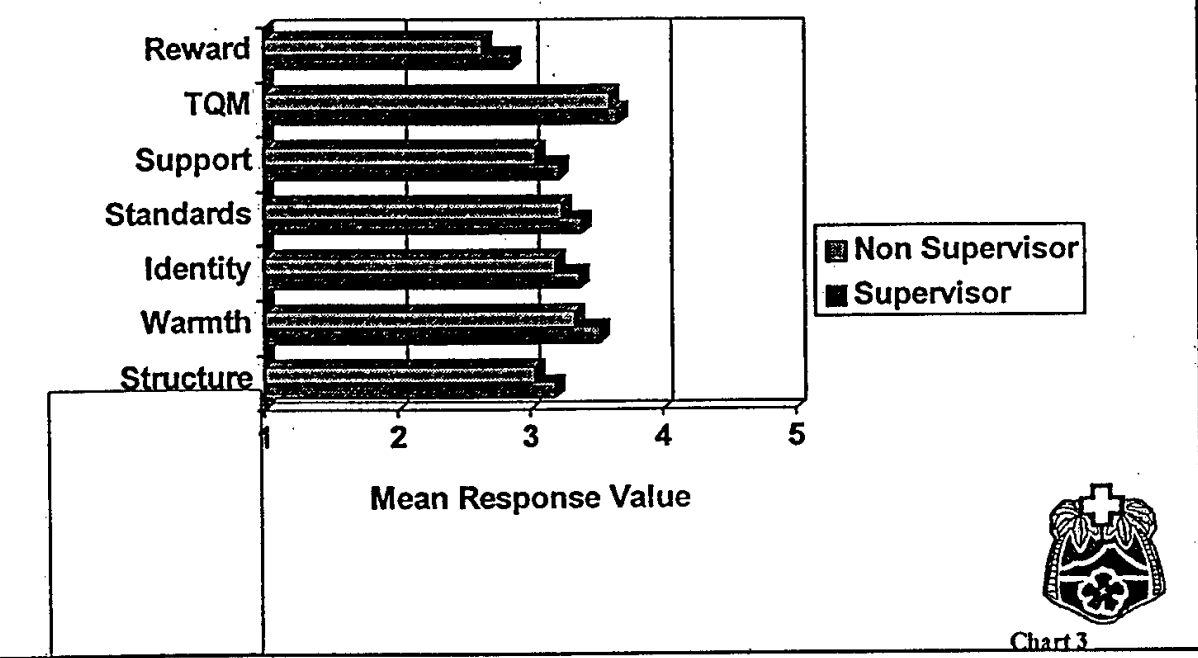

Tripler Regional Medical Center

\section{Make a mistake and you will be punished}

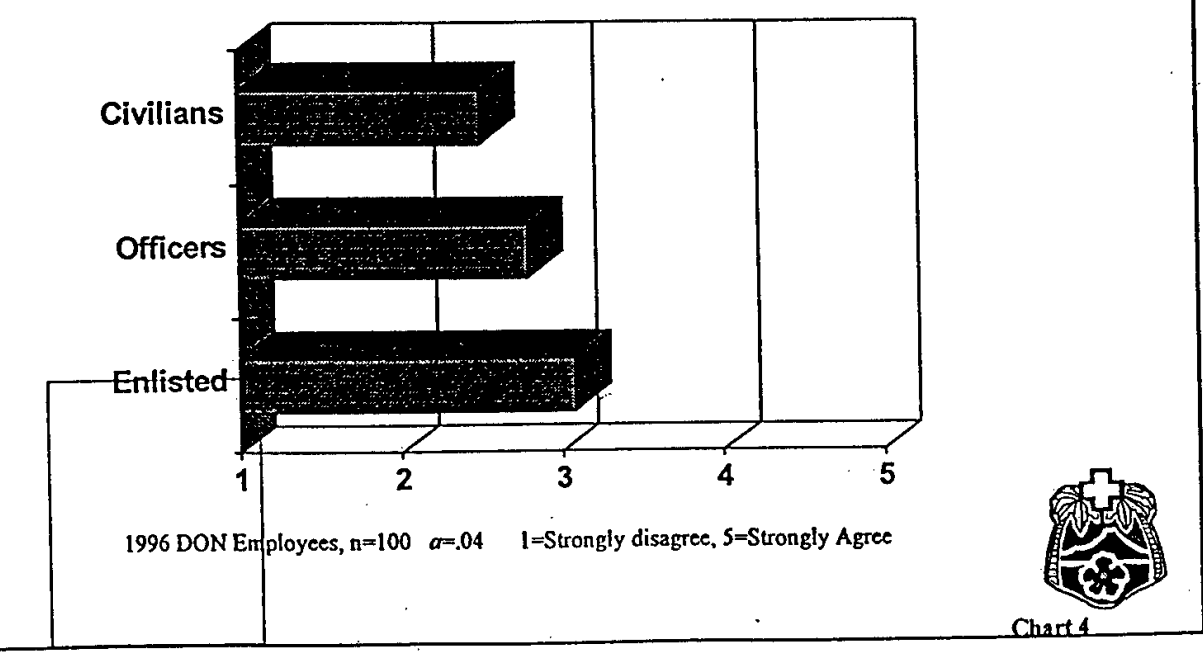


Tripler Regional Medical Center

\section{Management talks with you about career aspirations}

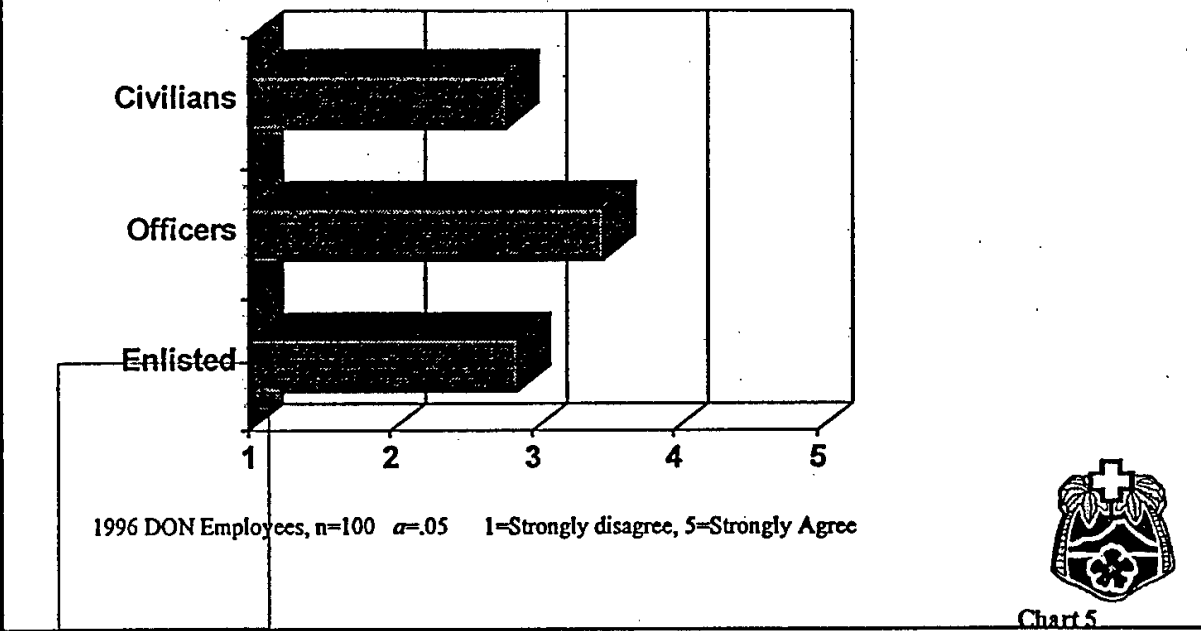

Tripler Regional Medical Center

\section{Management values how I feel}

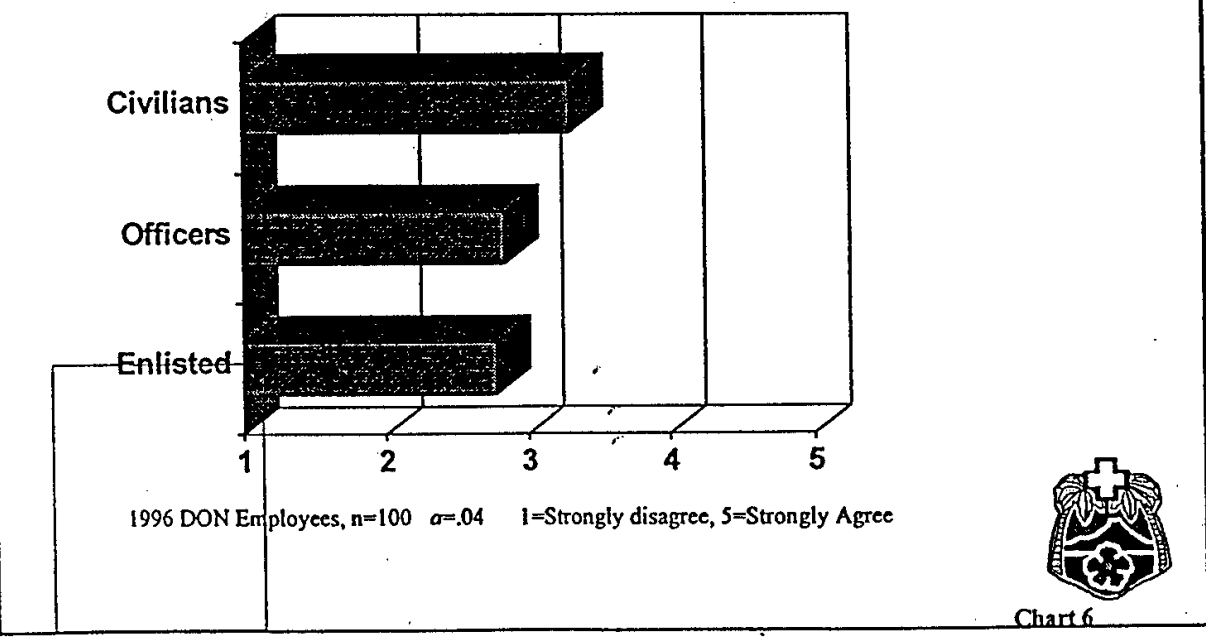


Tripler Regional Medical Center

\section{At TAMC, people don't take pride in} their performance

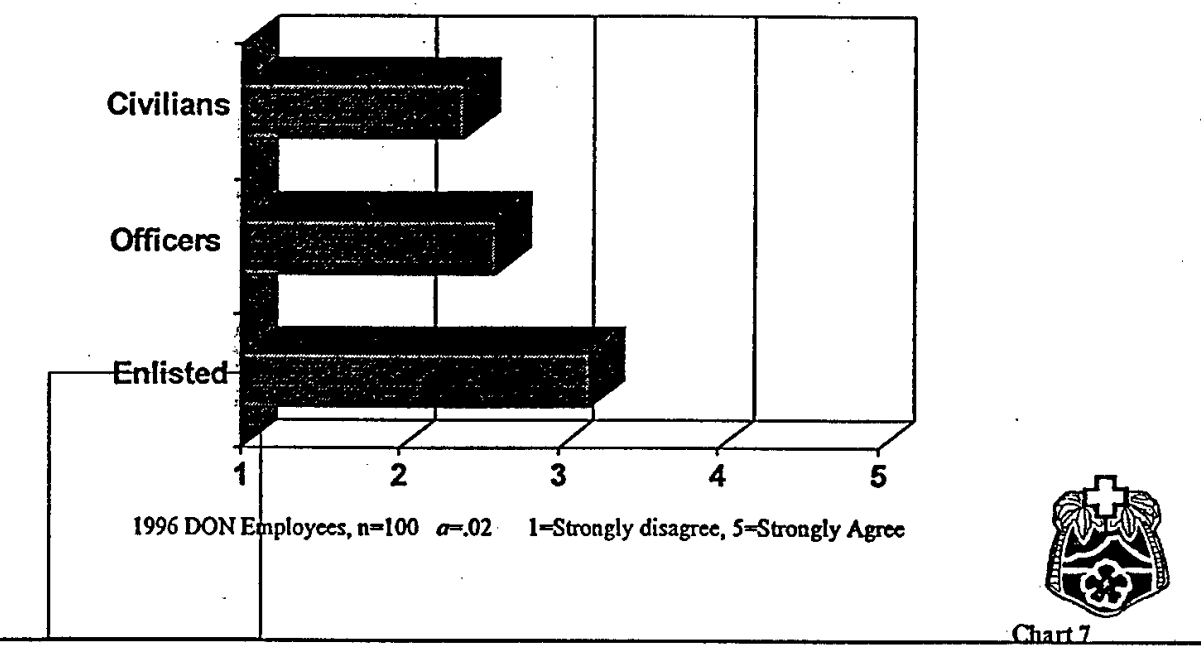

Tripler Regional Medical Center

Employees are encouraged to speak their minds, even if disagreeing

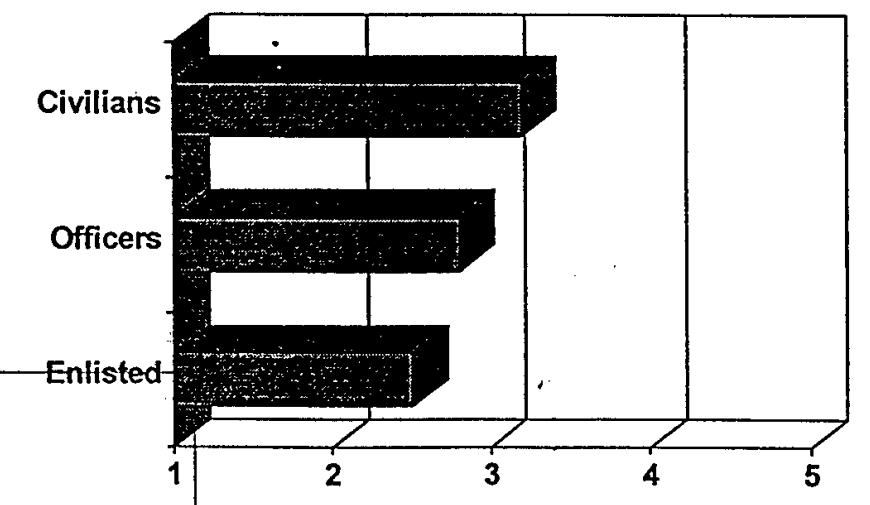

1996 DON Employees, $n=100 \quad a=.03 \quad$ l=Strongly disagree, $5=$ Strongly Agree

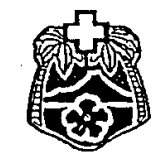


Tripler Regional Medical Center

\section{People are not loyal to Tripler}

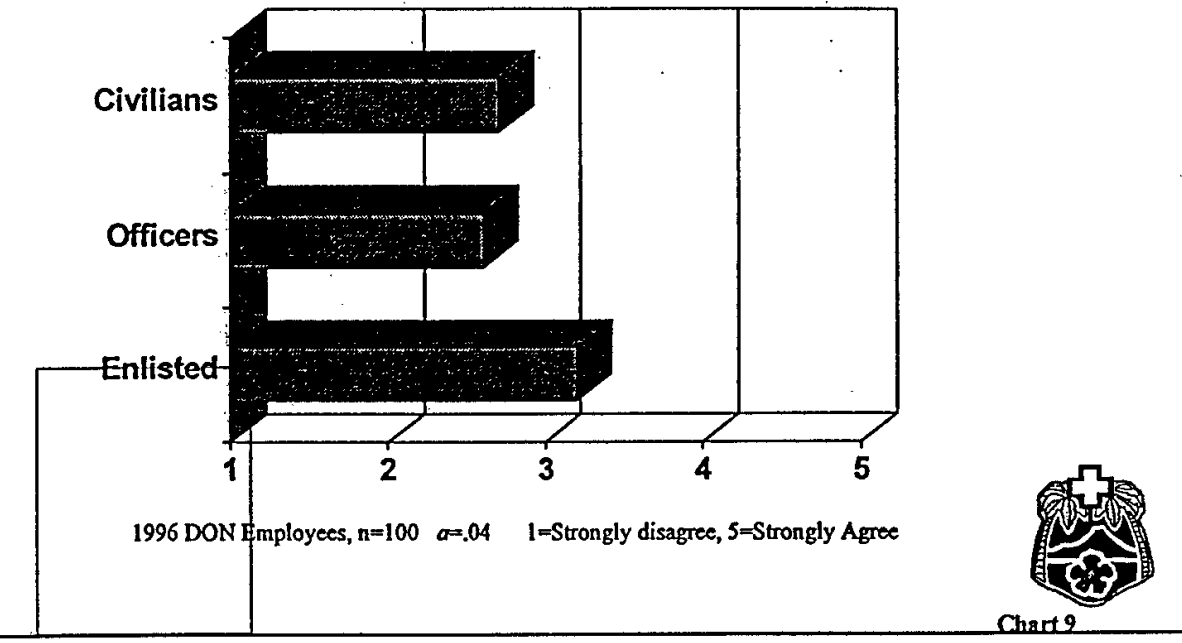

Tripler Regional Medical Center

People at Tripler just look out for themselves

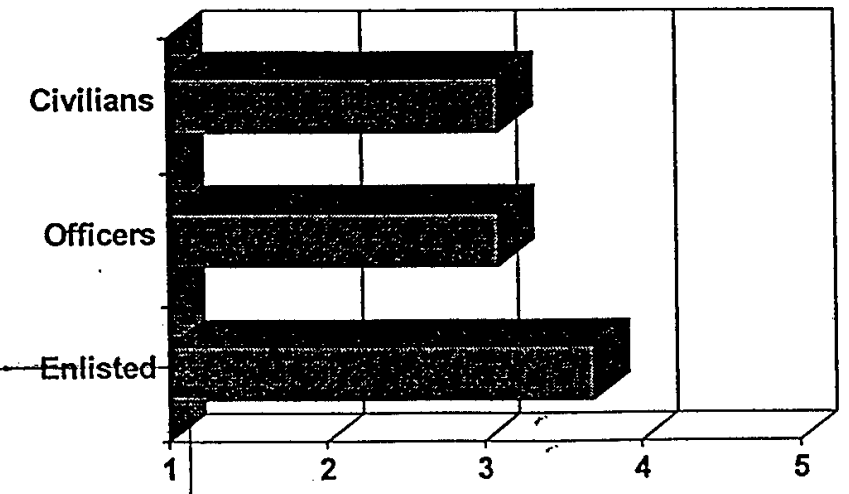

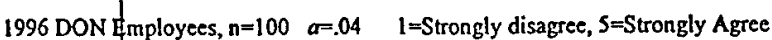

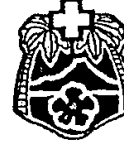




\section{WORKS CITED}

Arndt, Margarete, and Barbara Bigelow. 1995. The Implementation of Total Quality Management in Hospitals: How Good is the Fit? Health Care Management Review, 20(4), 7-14.

Berenson, Mark L. and David M. Levine. 1992. Basic Business Statistics: Concepts and Applications, $5^{\text {th }}$ ed. Prentice Hall, Inc. Englewood Cliffs, NJ.

Bigelow, Barbara, and Margarete Arndt. 1995. Total Quality Management: Field of Dreams? Health Care Management Review, 20(4), 15-25.

Boerstler, Heidi, Richard Foster, Edward J. O'Conner, James O'Brien, Stephen Shortell, James Carman, and Edward Hughes. 1996. Implementing Total Quality Management: Conventional Wisdom verses Reality. Hospitals and Health Services Administration, 41(2), 143-159.

Brown, R. A. and J. Swanson Beck. 1994. Medical Statistics on Personnel Computers. $2^{\text {nd }}$ Ed. BMJ Publishing Group, Plymouth, England.

Carman, James M., Stephen M. Shortell, Richard W. Foster, Edward F.X. Hughes, Heidi Boerstler, James L. O'Brien, and Edward J. O'Conner. 1996. Keys for Successful Implementation of Total Quality Management in Hospitals. Health Care Management Review, 21(1), 48-60.

Cooper, Donald R. and C. William Emory. 1995. Business Research Methods, $5^{\text {th }} \mathrm{Ed}$. Richard D. Irwin, Inc. Chicago.

Counte, M. A., G. L. Glandon, D. M. Hill, and J. P. Hill. 1992. Total Quality Management in a Health Care Organization: How are Employees Affected? Hospitals and Health Service Administration, 37(4), 503-518.

Cronbach, L. J. 1951. Coefficient alpha and the Internal Structure of Tests. Psychometrika, 16, 297-334.

Crosby, Philip B. 1986. Running Things: The Art of Making Things Happen, New American Library. New York.

Daniel, Wayne W. 1978. Biostatistics: A Foundation for Analysis in the Health Sciences, $2^{\text {nd }}$ ed. John Wiley and Sons, New York.

Ernst, Diane Fahey. 1994. Total Quality Management in the Hospital Setting. Journal of Nursing Care Quality, 8(2): 1-8. 
Floro, Frank C. 1994. An Assessment of the Organizational Culture of Tripler Regional Medical Center and its Impact on Total Quality Management. Graduate Management Project, U.S. Army Baylor Program in Health Care Administration. 1-78.

Fottler, Myron D., S. Robert Hernandez, and Charles L. Joiner. 1994. Strategic Management of Human Resources in Health Service Organizations, $2^{\text {nd }}$ ed. Delmar Publishers, Albany, NY.

Griffith, John R., Vinod K. Sahney, and Ruth A. Mohr. 1995. Reengineering Health Care: Building on CQI, Health Administration Press, Ann Arbor, MI.

Gustafson, David H. and Ann Schoofs Hundt. 1995. Findings of Innovation Research Applied to Quality Management Principles for Health Care. Health Care Management Review, 20(2), 16-33.

Health Care Financing Administration. 1996. National Health Expenditures. HCFA Press Release dated May 27, 1996. 1-2.

Health Care Financing Administration. 1996. National Health Expenditure Aggregates, Table 1-2. Cited from http://www.hcfa.gov/stats/tablkdf.txt and http://www.hcfa.gov/stats/tab2kdf.txt.

Jennings, Kenneth, and Fred Westfall. 1994. A Survey-Based Benchmarking Approach for Health Care Using the Baldrige Quality Criteria. The Joint Commission Journal on Quality Improvement, (September): 500-509.

Joint Commission. 1997. Doing the Right Things Right: Case Studies on Strategies for Maintaining Readiness. Oak Terrace, IL. Joint Commission Department of Publication.

Juran, J. M. and Frank M. Gryna, Jr. 1980. Quality Planning and Analysis, $2^{\text {nd }}$ ed. McGraw-Hill Publishing, New York.

Lickman, Patricia, Lillian Simms, and Connie Greene. 1993. Learning Environment: The Catalyst for Work Excitement. The Journal of Continuing Education in Nursing, 24(5), 212-216.

Litwin, G. H. and R. A. Stringer. 1968. Motivation and Organizational Climate. Boston Division of Research, Harvard University, Boston MA.

Motwani, Jaideep, Victor E. Sower, and Leon W. Brasher. 1996. Implementing TQM in the Health Sector. Health Care Management Review, 21(1), 73-82. 
Muchinsky, P. 1976. An Assessment of the Litwin and Stringer Organizational Climate Questionnaire: An Empirical and Theoretical Extension of the Sims and LaFollette Study. Personnel Psychology, 29(2), 371-92.

Plsek, Paul E. 1994. Tutorial: Planning for Data Collection, Part I: Asking the Right Question. Quality Management in Health Care, 2(2), 76-81.

Plsek, Paul E. 1994. Tutorial: Planning for Data Collection, Part II: Designing the Study. Quality Management in Health Care, 2(2), 76-81.

Plsek, Paul E. 1994. Tutorial: Planning for Data Collection, Part III: Sample Size. Quality Management in Health Care, 3(1), 78-92.

Rakich, J. S., B. B. Longest, and K. Darr. 1992. Managing Health Service Organizations, $3^{\text {rd }}$ ed. Health Professions Press, Baltimore.

Robinson, Robert K., Ross L. Fink, and Lisa A Fink. 1995. Employee Participation Programs in the Health Care Industry: Are They Lawful Under Recent Labor Rulings? Hospitals and Health Services Administration, 40(1), 124-137.

Solbach, M. Theresa, Thomas A. Atchison, and Kathryn E. Ryan. 1990. At The Core. Health Progress, (December): 42-47.

Spatz, Chris. 1993. Basic Statistics: Tales of Distribution. Brooks/Cole Publishing, Pacific Grove. 